\title{
DEMAND CONDITIONS AND WORKER SAFETY: EVIDENCE FROM PRICE SHOCKS IN MINING
}

\author{
Kerwin Kofi Charles \\ Matthew S. Johnson \\ Melvin Stephens Jr. \\ Do Q. Lee \\ Working Paper 26401 \\ http://www.nber.org/papers/w26401 \\ NATIONAL BUREAU OF ECONOMIC RESEARCH \\ 1050 Massachusetts Avenue \\ Cambridge, MA 02138 \\ October 2019
}

We thank Kurt Lavetti and Ryan McDevitt for helpful comments, and seminar participants at the 2018 ASSA meetings and UT Austin. Thanks also to Vanessa Stewart and Reza Noorani at MSHA for guidance on using the MSHA databases, and to Jeff Kohler, Linda McWilliams, and George Luxbacher for helpful details about the mining sector. The views expressed herein are those of the authors and do not necessarily reflect the views of the National Bureau of Economic Research.

NBER working papers are circulated for discussion and comment purposes. They have not been peer-reviewed or been subject to the review by the NBER Board of Directors that accompanies official NBER publications.

(C) 2019 by Kerwin Kofi Charles, Matthew S. Johnson, Melvin Stephens Jr., and Do Q. Lee. All rights reserved. Short sections of text, not to exceed two paragraphs, may be quoted without explicit permission provided that full credit, including $\odot$ notice, is given to the source. 
Demand Conditions and Worker Safety: Evidence from Price Shocks in Mining Kerwin Kofi Charles, Matthew S. Johnson, Melvin Stephens Jr., and Do Q. Lee NBER Working Paper No. 26401

October 2019

JEL No. J23,J28

\begin{abstract}
$\underline{\text { ABSTRACT }}$
We investigate how demand conditions affect employers' provision of safety - something about which theory is ambivalent. Positive demand shocks relax financial constraints that limit safety investment, but simultaneously raise the opportunity cost of increasing safety rather than production. We study the U.S. metals mining sector, leveraging exogenous demand shocks from short-term variation in global commodity prices. We find that positive price shocks substantially increase workplace injury rates and safety regulation non-compliance. While these results indicate the general dominance of the opportunity cost effect, shocks that only increase mines' cash-flow lower injury rates, illustrating that financial constraints also affect safety.
\end{abstract}

Kerwin Kofi Charles

School of Management

Yale University

165 Whitney Avenue

New Haven, CT. 06511

and NBER

kerwin.charles@yale.edu

Matthew S. Johnson

Duke University

Box \#90312

Durham, NC 27708

m.slater.johnson@gmail.com
Melvin Stephens Jr.

University of Michigan

Department of Economics

356 Lorch Hall

611 Tappan St.

Ann Arbor, MI 48109-1220

and NBER

mstep@umich.edu

Do Q. Lee

Department of Economics

New York University

19 West 4th Street, 5th Floor

New York, NY 10012

dq1204@nyu.edu 


\section{Introduction}

Workplace injuries and illnesses impose a substantial economic burden on society. These adverse events are both pervasive and extremely costly. In 2015 over 50 percent of workers reported being exposed to hazardous working conditions (Maestas et al., 2017), and 3 out of every 100 full-time workers experienced an occupational injury or illness ${ }^{1}$; moreover, workers injured on the job face a subsequent earnings penalty of $8 \%$ on average, and $30 \%$ for permanent disability (Dworsky et al., 2018). Workplace injuries generate other direct costs like medical care, as well as indirect costs like lost productivity. Leigh (2011) estimates the total social cost of U.S. workplace injuries and illnesses in 2010 was $\$ 250$ billion.

Limiting workplace injuries requires that firms make investments — e.g. upgrading worn-out capital equipment, training workers to avoid risks, routinely monitoring production equipment — and the return on such investments is potentially large. ${ }^{2}$ However, firms face tradeoffs and constraints in making safety investments. Credit constraints, for example, may limit firms' ability to undertake particular safety improvements (Cohn and Wardlaw, 2016; Rose, 1990a). Additionally, resources devoted to enhancing safety, such as workers' time, may come at the expense of production (Gowrisankaran et al., 2015). These considerations are similar to tradeoffs that govern firms' decisions about environmental performance (Greenstone et al., 2012). In general, our understanding of the empirical importance of factors that drive firms' safety investments remains incomplete.

In this paper, we study how changes in demand conditions firms face for their product affect workplace safety. Understanding the role of variation in product demand is important for several reasons. First, demand is of fundamental importance to all firms and thus paramount to every aspect of firms' decision-making. Second, as the theoretical model we present below illustrates, demand conditions have an ambiguous effect on safety decisions. Higher demand, and associated increase in price and profit, can ease a firm's financial constraints, enabling it to make valuable safety investments like replacing worn-out equipment. But favorable demand conditions also raise the opportunity cost of safety investments - such as worker training or regulating the speed of

\footnotetext{
${ }^{1}$ Bureau of Labor Statistics, "Employer-Related Workplace Injuries and Illnesses in 2015," October 27, 2016. Available at https://www.bls.gov/news.release/archives/osh_10272016.pdf.

${ }^{2}$ Numerous industry publications cite the positive return on investment in safety, e.g National Safety Council (2013). See also Kyle M. Morrison, May 21 2014, "The ROI of Safety,"Safety and Health, https://www. safetyandhealthmagazine.com/articles/10414-the-roi-of-safety
} 
production - that may come at the expense of current output. Whether demand shocks improve or impair safety is thus an empirical question. A central challenge to studying this question empirically, however, is that individual firms' demand is typically endogenous to firm attributes and/or market forces. We overcome this challenge by leveraging a setting with demand shocks exogenous to firm behavior, enabling us to analyze how demand shocks affect safety investments as well as other firm decisions.

After formalizing the intuition above that a demand shock has offsetting effects on firms' safety, we investigate this relationship empirically in the U.S. metals mining sector. The mining sector may be the ideal setting to study this relationship. First, mining has historically been, and continues to be, one of the most dangerous industries for workers. In 2016, 3.6 out of 100,000 full-time workers across all private industries experienced a fatality. By contrast, in mining the comparable fatality rate was nearly three times higher, at 10 deaths per 100,000 workers. ${ }^{3}$ Second, fluctuations in global commodity prices yield exogenous shocks to mines' demand that vary across commodities and over time. Third, each mine in the U.S. is required to report its injuries, illnesses, employment, and other related measures for each quarter that it is in operation. We construct a database of quarterly global prices spanning three decades for 16 metal commodities, the most comprehensive such database of which we are aware, and combine this information with mine-level data on employment, safety outcomes, and assessments from routine government safety inspections.

Using our dataset, we first analyze the impact of demand shocks - measured by quarterly changes in the price of the commodity a mine produces - on mines' production decisions. These shocks have a small effect on production at the extensive margin as measured by the number of actively producing mines. However, we find that these shocks have a large effect on the intensive margin: following a one percent increase in its commodity price, a mine increases its total employment by 0.23 percent, and its total working hours by 0.33 percent, the following quarter.

We next examine the relationship between demand shocks and worker safety. We find that mines experience substantially higher injury and illness rates following positive demand shocks. A one-percent exogenous increase in output price leads to 0.15 percent more injuries and illnesses per full-time worker. This result suggests that increases in output prices raise the opportunity cost

\footnotetext{
${ }^{3}$ Bureau of Labor Statistics, Census of Fatal Occupational Injuries, 2016, available at https://www.bls.gov/iif/oshcfoi1.htm\#rates, accessed June 2019.
} 
of worker safety, and that this effect dominates any easement of financial constraints that hinder safety investments. This estimate is highly robust to several specifications and functional forms. The effect of price shocks on injuries is not purely driven by changes in the average job tenure of mines' work force, the number of hours that workers work, or by affecting workers' willingness to report injuries.

Using data from routine government safety inspections, we also find that mines' exhibit worse compliance with safety and health regulations following a positive price shock, implying that firms reallocate effort away from safety and to production. A one-percent commodity price increase leads to .13 percent more violations of safety and health regulations. In addition, we find a large increase in violations which the inspector assessed to result from a negligent or willful act by the employer, bolstering the idea that demand shocks affect firm owners' inputs into safety investments.

Overall, our results imply that positive demand shocks impair workplace safety. This finding might appear to be at odds with an existing literature which finds that higher profitability and positive cash flow shocks improve workplace safety. To reconcile these seemingly contradictory results, we isolate one way that price shocks affect mines' cash flow without affecting their opportunity cost of safety: mining companies' internal corporate networks. Many mines in our sample are owned by a corporate parent that also owns mines that produce other commodities. Prior work has highlighted how firms distribute cash flow generated by one of its establishments to other establishments in its corporate internal network (Williamson, 1975; Giroud and Mueller, 2017). Given this organizational feature of firms, changes in the price of a commodity produced by a mine's corporate sibling (that is, another mine owned by the same corporate parent) may affect the first mine's cash flow, through redistribution by the corporate parent, but leave its opportunity cost of safety unaffected. Consistent with this, we find that an increase in the price of commodities produced by a mine's corporate sibling has a negative effect on its injury rate, in contrast to a change in its own price which has a positive effect. These results suggest that both opportunity costs and financial constraints have meaningful impacts on the safety and health of a firm's workers.

Our study contributes to multiple literatures. We extend a literature examining the economic determinants of workplace injuries and illnesses (e.g., surveyed in Ruser et al. (2010)). Prior work has examined the effects of workers' compensation (e.g., surveyed in Kniesner and Leeth (2014)), including insurance premiums (Moore and Viscusi, 1989), experience rating (Ruser, 1991; 
Thomason and Pozzebon, 2002) and benefit levels (Fishback, 1987; Krueger, 1990) on safety as well as government safety and health regulations and inspections (Levine et al., 2012; Li and Singleton, 2019). Economists have long understood job safety as an equilibrium outcome of firm and worker decisions traded off against wages (Rosen, 1986); such studies typically consider firms' costs of reducing injuries as time-invariant, whereas our paper highlights how the (opportunity) cost of firm safety investigates is sensitive to its demand conditions. Our study provides a micro-level analysis to a literature, exemplified by Ruhm (2000), which finds that health outcomes tend to be worse in economic booms than in recessions.

Three recent papers are especially similar in spirit to ours. Gowrisankaran et al. (2015) estimate the tradeoff between productivity and safety in the context of U.S. coal mining, and Caskey and Ozel (2017) find that pressure to meet earnings expectations leads to higher injury rates. Hummels et al. (2016) find that positive export-driven demand shocks lead to higher rates of worker injuries and sickness. Our results complement this latter paper. While their focus is on how demand shocks affect worker effort, and in turn their health outcomes, we in contrast focus on the effect on employers' incentives regarding safety. We also consider effects of more short-term, transitory shocks to profitability, whereas their paper considers the effect of a one-time, permanent shock.

Finally, our results contribute to prior studies that have investigated how firms respond to demand shocks. Prior work has investigated how demand shocks affect firms' growth (Ferraz et al., 2015) and wages (Abowd and Lemieux, 1993; Garin and Silverio, 2017; Atkin et al., 2017). We complement and extend this literature by investigating how demand shocks affect a critical aspect of firms' organizational performance and non-wage job attribute, workplace safety.

\section{Theoretical Framework}

In this section, we provide a simple model to formalize the intuition of how the demand for a firm's product affects its workers' safety and health. Our model clarifies two contrasting effects. A positive shock to demand - manifested in a positive shock to the price of the firm's outputincreases the financial resources at the firm's disposal to make valuable safety investments, which prior literature has illustrated is an economically meaningful relationship. On the other hand, a positive demand shock increases the opportunity cost of safety inputs that come at the expense of 
production. Which of these effects dominates will depend on firms' production processes.

We consider a setting in which firms each produce output $q$ for sale on a competitive global market at a price of $\$ p$ per unit. An unfortunate by-product of the prevailing technology is that workers at a firm $i$ experience a total amount of accidents, $A(i)$ over a given amount of time spent in production activity. Our analysis focuses mainly on understanding changes in this accident flow at a firm.

\section{Accident Technology}

Three factors determine a firm's accident flow. One of these is the intensity of production; accidents rise as firm increases output per unit of time. As resources are used more intensively to increase output, there is a mechanical increase in the likelihood of slippage, error, exhaustion, inattention - any number of things that make accidents more probable. We make the intuitively-appealing assumption that work becomes increasingly more dangerous as the intensity of production rises. As production expands, the firm must move into ever-more inherently unsafe settings or practices. In the case of mining, for example, which is the industry we study empirically below, producing ever more output requires that the firm move ever deeper underground. More generally, an increasing marginal riskiness of production could also reflect diminishing marginal product of labor.

Accidents are also affected by how much safety-enhancing training, $T$, a firm provides its workers. This training requires some of a worker's time and may also use other productive resources. As a result, safety training comes at the expense of some lost output, so $T=T(q)$ with $T^{\prime}<0$ and $T^{\prime \prime} \leq 0$. The third determinant of the firm's accident flow is the firm's investment in safety-related equipment, $E$, such as resources spent replacing worn-out machine parts or spending on new technology for stable ground control. We assume that the effectiveness of an additional unit of training declines the larger the amount of such training already done. We make the same assumption of diminishing returns about the benefits of additional investments in safety equipment.

Accidents can, therefore, be thought of as being "produced" according to the function $A(q, T(q), E)$, 
with

$$
\begin{array}{lll}
A_{q}=\frac{\partial A}{\partial q}>0 ; & A_{T}=\frac{\partial A}{\partial T}<0 ; & A_{E}=\frac{\partial A}{\partial E}<0 ; \\
A_{q q}=\frac{\partial^{2} A}{\partial q \partial q}>0 ; & A_{T T}=\frac{\partial^{2} A}{\partial T \partial T}>0 ; & A_{E E}=\frac{\partial^{2} A}{\partial E \partial E}>0 .
\end{array}
$$

For the sake of exposition, we make the strong, but plausible, assumption that the inputs into the firm's "accident production function" are separable. That is, for example, the degree to which increasing production elevates accident risk is invariant to the level of safety equipment or training. Boosting production may increase accidents due to higher worker fatigue, and the marginal effect of fatigue may be independent of equipment and training. Additionally, training and equipment could have independent effects on the likelihood of accidents. ${ }^{4}$ Importantly, this assumption is not critical to our model's predictions; we derive the model's comparative statics relaxing this assumption in Appendix A, where we show that each of the predictions that follow remain largely unchanged.

\section{Firm's Problem}

Safety equipment, $E$, is expensive. To capture the idea that some firms may face liquidity constraints that limit their ability to undertake these capital investments we assume that each firm $i$ can rent equipment at a per unit price of price of $R(i)$, which varies across firms. The rental price that a particular firm pays is determined by overall credit-worthiness and overall financial position (i.e. the strength of its balance sheet). A key driver of a firm's balance sheet and thus of its financial position is the market demand for its output, as reflected in the market price, $p$, at which the firm can sell the product. In addition to output demand, other (mostly unobserved) factors such as debt or management structure, likely affect a firm's financial standing and, by extension, the extent to which it might be liquidity constrained in the purchase of capital equipment. Call these other drivers of credit-worthiness $x(i)$. Thus, the rental price a firm pays is $R(i)=R(p ; x(i))$. We assume that $R^{\prime}=\partial R(p ; x(i)) / \partial p<0$.

Accidents are costly to a firm. In particular, for a given flow of accidents, the firm incurs some $\operatorname{cost} \kappa$, which represents the combined effect of compensating wage differentials it must pay workers; higher workers' compensation premiums; higher contributions to the disability system; or even the

\footnotetext{
${ }^{4}$ This assumption could be violated if, for example, the amount by which increased production raises accidents is smaller the higher the level of training and the higher the level of safety equipment.
} 
negative effect upon sales that adverse publicity from accidents to the firms' workers brings.

A profit-maximizing firm chooses a level of output $q$ and buys (or finances) safety equipment $E$ to maximize ${ }^{5}$

$$
p \times q-\kappa \times A(q, T(q), E)-R_{i}(p, x) \times E .
$$

Note that, because training $T$ is a function of $q$, by choosing a level of $q$ the firm simultaneously chooses how much training $T$ it provides. The optimal levels of output and safety equipment that solve this problem, $q^{*}$ and $E^{*}$, are given by the first order conditions

$$
\begin{aligned}
p-\kappa\left[A_{q}\left(q^{*}, T^{*}, E^{*}\right)+A_{T}\left(q^{*}, T^{*}, E^{*}\right) T^{\prime}\right] & =0 \\
-\kappa A_{E}\left(q^{*}, T^{*}, E^{*}\right)-R_{i} & =0 .
\end{aligned}
$$

The optimizing firm produces output up to the point where its gain from the last unit it makes (the price $p$ for which that unit can be sold) equals its increase in cost. This increased cost is the market price paid for marginally higher accident flow times the increase in the accidents from higher output on the one hand and reduced time and effort on safety training on the other. With respect to safety equipment, the firm will spend on safety equipment until the reduction in accident costs from more equipment equals its rental price for these items.

\section{Comparative Statics of an Exogenous Output Price Increase}

We are interested in how a shock to the market demand for its output, as reflected in a change in the output price $p$, affects the accidents a firm's workers experience, i.e. $\frac{d A}{d p}$. This comparative static depends on $\frac{\partial q}{\partial p}$ and $\frac{\partial E}{\partial p}$, the signs of which we determine by applying Cramer's Rule to Equation (2), and using second-order optimization conditions.

From this analysis, we have that

$$
\frac{\partial q}{\partial p}=-\frac{\kappa\left(-A_{E E}\right)}{\operatorname{det}(H)}
$$

\footnotetext{
${ }^{5} \mathrm{~A}$ more realistic model might have the firm choosing its labor input, with production being a function of labor and with the wage either as a parameter or an outcome determined in equilibrium, etc. We instead present a stylized model that seeks to formalize the intuition that distinguishes our focus on the effect of demand shocks on safety from prior work on how firms' financial condition, broadly defined, affects safety, Though we abstract away from important elements that affect firms' decisions regarding safety, we believe that such extensions would not appreciably change the insights that our model yields.
} 
where $\operatorname{det}(H)$ is the determinant of the Hessian matrix of second derivatives. Given our assumptions about the partial derivatives above, the numerator is negative, and the denominator must be positive by the second order conditions, making the entire term positive. Thus, $\frac{\partial q}{\partial p}>0$. This result makes immediate intuitive sense: a profit-maximizing firm increases production when a positive demand shock (as reflected in the rise in price), makes its output more valuable.

Employing similar reasoning, we have that

$$
\frac{\partial E}{\partial p}=-\frac{\kappa \times\left(R_{p} \times\left(A_{q q}+A_{T} T^{\prime \prime}+A_{T T} T^{\prime} \times T^{\prime}\right)\right)}{\operatorname{det}(H)}
$$

The numerator is $<0$ given the assumptions on the partial derivatives, making the entire term positive. Thus, $\frac{\partial E}{\partial p}>0$. This result also makes intuitive sense. An increase in the firm's output price lowers its cost of obtaining equipment, which leads the firm to purchase more of it.

From these results it follows that, a change in output price, deriving from an exogenous shock to demand, has an effect on accidents given by

$$
\frac{d A\left(q^{*}, T(q)^{*}, E^{*}\right)}{d p}=\underbrace{A_{q} \frac{d q^{*}}{d p}}_{>0}+\underbrace{A_{T} \frac{d T}{d q} \frac{d q^{*}}{d p}}_{>0}+\underbrace{A_{E} \frac{d E^{*}}{d p}}_{<0} .
$$

Expression (5) shows that an increase in output price affects accidents via three channels. Two of these effects would, by themselves, lead to a higher accident flow when demand conditions are good. Higher prices induce the firm to increase output to take advantage of the higher revenue possibilities. This increase in output shifts resources away from safety training and towards production. Both these actions tend to increase accidents. On the other hand, a firm facing higher demand for its output will be a good financial position and thus able to borrow or finance directly the purchase of safety equipment, which would tend to reduce accidents. This liquidity-easing consequence of a higher output price acts in the opposite direction of higher accidents associated with increased output, making the overall effect of an exogenous demand shock on accidents ambiguous.

\section{Comparative Statics of Other Changes in Firm's Financial Position}

It is useful to examine the effect of other shocks that, like changing product demand, alter the firm's financial position. Prior literature has studied how factors that make a firm's financial situation 
better, such as lower financing constraints, affect accidents. How is this kind of change captured in our framework, and how does its predicted effects on accidents differ from what we show above for exogenous price changes?

Consider a shock that only affects a firm's financial constraints, but has no effect on the price of the firm's output. In our framework, this kind of shock is represented by a change in one of the factors $x(i)$ that, along with output price, $p$, determine how much the firm pays to rent capital equipment, $R(i)$.

The effect of this shock on accidents is thus $\frac{d A}{d x}$. How $x$ affects the firm's choice of $q$ and $E$ is given by:

$$
\begin{aligned}
& \frac{\partial q}{\partial x}=0 \\
& \frac{\partial E}{\partial x}=-\frac{R_{x}(i) \times \kappa\left(A_{q q}+A_{T T} T^{\prime} \times T^{\prime}+A_{T} T^{\prime \prime}\right)}{\operatorname{det}(H)}>0
\end{aligned}
$$

where, as before, $\operatorname{det}(H)$ is the determinant of the Hessian matrix, $H$, that is the matrix of second derivatives with respect to $q$ and $E$.

Going in reverse order, Equation (7) reveals that, predictably, a positive liquidity shock leads the firm to increase its investment in $E$ by the same intuition as an increase in its output price.

On the other hand, a change to liquidity has no effect on firms' output. This is because, unlike a change in the firm's output price, a change in its liquidity position leaves its value of production (and opportunity cost of training) unchanged. ${ }^{6}$

Thus, a pure improvement to a firm's financial position leads to unambiguously fewer accidents, an implication that is consistent with prior studies finding that improvements in firms' financial constraints reduce injuries (e.g. Cohn and Wardlaw (2016) and Rose (1990b))

\section{Empirical Predictions}

This framework guides our empirical analysis the following way. First, we seek to examine the effects of price shocks on firms' accidents, which our framework shows to have a theoretically ambiguous direction. Second, we aim to compare the effects of price shocks on accidents to the effects of pure changes to firms' financial position. Our analysis above implies that a positive shock to financial

\footnotetext{
${ }^{6}$ As shown in Appendix A, a liquidity change might affect output if accident inputs are non-separable.
} 
constraints unambiguously leads to fewer accidents. We next turn to our setting where we examine these relationships empirically.

\section{Metal Mines in the U.S.}

\subsection{Worker Safety and Health in Metal Mines}

We focus on mining in the U.S. of globally-traded metals. Our analysis therefore excludes mining in coal, construction sand and gravel. Mines are typically either surface or underground, with the distinction stemming from the mine's geological constraints. Surface mining involves the removal of the soil and rock overlaying the desired mineral to reach buried deposits. Underground mining, on the other hand, leaves the overlaying earth in place and consists of digging tunnels or shafts into the earth to reach buried deposits.

Mining remains a dangerous industry for workers. This is chiefly because of risks inherent in the production process, such as explosions, flooding, cave-ins, and other accidents resulting from unstable ground conditions. In 2016, 3.6 out of 100,000 full-time workers across all private industries experienced a fatality. By contrast, in mining the comparable fatality rate was nearly three times higher, at 10 deaths per 100,000 workers. ${ }^{7}$ Non-fatal injury rates, on the other hand, actually tend to be lower in mining than the private sector as a whole. ${ }^{8}$

Mines can undertake many actions and investments that enhance safety. ${ }^{9}$ Some actions require significant financial investment, including purchasing and upgrading equipment like belt lines, storage facilities for explosives, etc. Other safety inputs may require not just financial investment, but also substantial time to implement. A clear example of a time-intensive input is providing safety training to ensure that workers are informed of the hazards associated with specific jobs and instructed on precautionary measures such as proper use of personal protective equipment. Another time-intensive input, so far as it disrupts production, is maintenance, housekeeping and cleanliness. The International Labor Organization, for example, suggests that mines routinely have personnel inspect the personal protective equipment to monitor whether they are in good condition

\footnotetext{
${ }^{7}$ Bureau of Labor Statistics, Census of Fatal Occupational Injuries, 2016, available at https://www.bls.gov/iif/oshcfoil.htm\#rates, accessed June 2019.

${ }^{8}$ BLS Workplace Injury, Illness and Fatality Statistics, available at https://www.osha.gov/oshstats/work.html, acesssed December 2018.

${ }^{9}$ This section draws heavily from Organization (2006) and Walle et al. (2001).
} 
or in need of repair. Since one of the leading causes of accidents in this sector is unstable ground conditions, it is crucial for miners to ensure that hazardous ground conditions be supported before any work. Another time-intensive input is arranging working hours to ensure that workers have adequate time for rest. Given that long work hours can lead to fatigue and make workers more injury-prone (Dembe et al., 2005), limiting workers' shifts can reduce injuries.

Every mine in the US is under the jurisdiction of the Mine Safety and Health Administration (MSHA), the regulatory body charged with setting and enforcing standards to promote safety and healthy workplaces for all miners. Since the 1980s, each mine has been required each quarter to report to MSHA statistics related to its operations and safety and health performance: such as whether it was in operation, its number of workers and total hours worked in different roles, the number of various types of injuries and illnesses it experienced, etc. Mines must also report on their corporate stricture, in particular their ultimate corporate owner (called a "controller" in the industry). Furthermore, MSHA inspects mines on a regular basis to check whether a mine is complying with its standards. If the inspector discovers that a mine is violating any MSHA standards, she issues a citation for each violation, and MSHA eventually requires the mine to pay financial penalties for each citation.

\subsection{Determinants of Commodity Prices}

While many commodities mined in the U.S. are traded on local or regional markets, a subset of metals are traded on global markets. Global commodity prices can be driven by an array of market forces outside the control of individual mines. For example, the price of gold - which is primarily a monetary asset - is a function of interest rates, currency values, and the stock market, all of which affect the perceived value of holding assets like gold. The price of other precious metals like silver and platinum can also be subject to idiosyncratic speculation in financial markets. Furthermore, because these metals are primarily used for industrial purposes, they face additional price shocks driven by variation in industrial activity (Popescu, 2014). The price of uranium, which is a key input into nuclear power, can be affected by worldwide demand for nuclear power.

Metals also differ with respect to factors that dictate their supply. Metals vary in the geographic distribution of deposits around the world, with many concentrated in countries characterized by unstable institutions. Therefore, geopolitical issues that affect mine production in Kazakhstan, a 
large producer of uranium, will affect uranium prices very differently than gold prices. As a concrete example, the dissolution of the Soviet Union in 1989 directly affected the price of aluminum: in need of hard currency following dissolution, Russia - a large suppler of aluminum - put large quantities of aluminum on the world market. This sudden increase in aluminum supply, not met with a corresponding change to demand, depressed world aluminum prices yet had little if any effect on other commodity prices (Plunkert and Jones, 1999). In sum, metals each face their own idiosyncratic set of factors affecting both their demand and supply, and hence their price.

Not only do globally traded precious metals face idiosyncratic price shocks, but individual mines are price takers and unable to single-handedly affect price. For gold, for example, it is estimated that mine production contributes a mere $1.64 \%$ to the total annual gold supply (Popescu, 2014), meaning that aggregate production - let alone an individual mine's production - is inconsequential to price movements. Table 3 illustrates further how U.S. mines that produce globally-traded metals are price takers. For each of the 16 commodities in our eventual sample (described below), the table provides various metrics of market concentration. The first two columns provide the U.S. rank in terms of 2014 production and the country that accounts for the largest share of production. The columns that follow provide total U.S. and global production, as well as the U.S. share of global production. These columns make clear that U.S. production as a whole - and obviously, that of an individual mine - account for, at most, a tiny share of overall production of each of these commodities, and thus is unlikely to be a key determinant to global prices. The U.S. is not the highest-ranking producer of any commodity, and for the majority it ranks fifth or lower. Moreover, the U.S. accounts for less than 10 percent of production in all commodities except molybdenum, for which the U.S. makes up 22 percent of production.

Even though the U.S. does not make up a substantial share of production, one might worry that these markets are not characterized by significant competition. To address this concern, the table also presents calculations of the Herfindahl-Hirschman Index (HHI), both for the U.S. and for the world. The HHI, calculated as the sum of the squares of market shares of each producer, is a measure of market concentration. The index ranges from 0 , indicating perfect competition, to 10,000, indicating a sole monopoly. For each commodity the HHI for U.S. producers is tiny, with all except molybdenum below 100 . 


\subsection{Effects of Prices on Production Decisions of Mines}

While individual mines' production does not affect prices, global prices almost certainly influence individual mines' production decisions by affecting the value of production. Prior work has illustrated that fluctuations in price caused by swings in demand lead to movement along the supply curve for gold (Rockoff, 1984), as well as production decisions of individual coal mines (Ellerman et al., 2001).

The cost structures of mining makes clear why variation in prices has a strong effect on mines' production and investment decisions. ${ }^{10}$ Because metal mines can have steep variable costs of production, the price level can dictate the level of production that is economically viable. Within a given mine, there may be sections that are only cost-effective to mine if the price is high enough.

Figure B.1 illustrates the relationship between prices and annual U.S. production for the commodities Silver and Gold. The figure plots the year-over-year log change in total U.S. production against the lagged year-over-year change in price for the period 1984-2005. Both series come from the U.S. Geological Survey. For both metals, changes in prices appear to predict changes in production.

Prices affect production decision not only in existing mines, but also investment decisions in new mines. Figure B.2 shows the strong correlation between mining companies' budgets for exploration and current commodity prices. This relationship is consistent with recent models of how prices affect drilling decisions in the oil industry (Anderson et al., 2018). At the same time, there can often be a long lag between the initial exploration of a new mine and the start of production activity. Given this lag between price signals and realized production from new investment, production and investment responses by mining companies can, in theory, amplify boom and bust cycles in commodity prices. Such actions can potentially be driven by forecasting errors, in which firms have two kinds of biased expectations: failing to accurately forecast demand shocks as being more persistent than they actually are, and failing to anticipate the endogenous response of other suppliers of their competitors (Greenwood and Hanson, 2014).

The responsiveness of production to prices may also differ across types of mines. In particular, underground mines may be more likely than surface mines to respond to changes in prices for two

\footnotetext{
${ }^{10}$ This section draws on a phone call with George Luxbacher at the Center for Disease Control, who provided helpful background on how prices affect production decisions in mines.
} 
reasons. First, surface mines face constraints in their ability to expand production that underground mines do not. Surface mining is generally conducted in an open pit, and the boundaries of these pits, or "pit limits," are pre-determined before the mining operation even begins (Newman et al., 2010). Thus, while operators of surface mines can expand or contract variable inputs of production (e.g. workers, shovels), they face strict limits in their ability to expand output. Underground mines face no equivalent to pre-determined pit limits. Underground mines have more abilities to expand or contract, for example by digging new tunnels into areas that may only be economically feasible if the price of the metal is high enough.

Second, the fixed and variable costs of underground mining are higher than for surface mining, meaning that prices may be much more likely to dictate production decisions in underground mines. In terms of fixed costs, underground mining requires considerable capital requirements, such as proper ventilation systems to supply necessary oxygen to miners working underground, and to carry away the hazardous components of mine air, which can include potentially explosive methane gases (Harvey, 2015). Ground control conditions are also typically much riskier in underground than surface mines, requiring extra costs to manage them (Beauchamp, 1998). In terms of variable costs, underground methods require more operating costs (e.g. more electricity to cool deep underground shafts), and labor costs are also more expensive in underground mining due to higher health care and benefits liabilities, and greater need for skilled labor (Chen, 2014).

An illustrative example of how price changes affect the extensive margin of production among underground mines is given by the Tropicana Gold Project, jointly developed by AngloGold Ashanti and the Independence Group. In the 2000s, anticipating a rise in gold prices, the firm had planned to develop a gold deposit located at the western edge of the Great Victoria Desert in Australia. The site, dubbed as the "Tropicana Gold Belt," had previously been unexplored due to its remoteness. A $220 \mathrm{~km}$ road had to be built to access the mine, along with a 40 megawatt power station to supply the mine site with electricity (IGO, 2015). Due to economic constraints, the Tropicana Gold mine could not be developed at the time of planning, but as gold prices increased in the second half of the 2000s, the Independence Group decided it was feasible to develop the remote gold mining site, and the site was developed as gold prices increased to a 10-year high during 2010 (Chambers, 2009). In other words, the increase in the price of gold led this company to expand into underground pits that would not be economically viable to mine if the underlying commodity price were lower. 
Economic theory tells us that the marginal unit of production following price changes will be more costly than the mine's average cost of current production; it is also likely (as we presume in our theoretical model) that this marginal unit is also more dangerous. In the case of mining, "ground control conditions," or the stability of the excavation process, are a leading cause of accidents in the mining sector and are also very expensive to manage, requiring specialized support systems, technical care regarding the speed and sequence of extraction, and mechanized monitoring systems. Areas with unstable ground control conditions may only become viable to enter when the price is

high enough. This increasing marginal danger of production likely generalizes to many sectors beyond mining: for example, firms may strive to meet short-term demand shocks by utilizing previously mothballed, less-safe equipment (Ruser, 1995). This increasing marginal injury risk of production is consistent with the model presented in Section 2 and will augment any effect of price shocks on managers' perceived opportunity costs of safety.

\section{Data and Measures}

\subsection{Price Data}

To measure the output price that a mine faces at a given time, we created a unique panel dataset of quarterly prices for commodities mined in the U.S. that are traded on world markets. We exclude commodities traded on local markets, such as Clay, Construction Sand and Gravel, Limestone, etc. Markets for such commodities are typically characterized by individual buyer-seller relationships, and as such there is no single "market price" for such commodities. Furthermore, individual mines for such commodities traded locally may be able to influence price by varying supply. By focusing on commodities traded on global markets, we ensure individual mines are price takers and that movements in a commodity's global price equally affects all mines producing that commodity.

We assembled our dataset from four sources. Our main source is the London Metal Exchange (LME), the world's largest market for financial contracts on metals. For commodities not covered in the LME database, we use prices from the International Monetary Fund (IMF) Primary Commodity Prices database. To further expand our set of commodities, we use Datastream to access the quarterly cash price 1983-2015 for metals in the MSHA database. The prices from Datastream are derived from a number of sources including Standard \& Poors and Thompson Reuters. Finally, for 
commodities not included in any of the databases above, we obtain additional data from Bloomberg.

In all, we collected data for 16 commodities. We standardized series from different sources by converting output prices to nominal U.S. dollars per metric ton of the underlying commodity. Table 1 lists the commodities included in our dataset, the years for which we have price data for each commodity, and the number of observations and unique mines for each commodity in our mine-level dataset.

Figure 1 shows the time series of our 16 standardized prices from 1983 to 2015. To facilitate comparability across commodities, in this graph we standardize each price series by subtracting the commodity-specific mean and dividing by the commodity-specific standard deviation. While movements in prices are correlated, there is also much idiosyncratic variation. Starting in the late 2000s, many commodities exhibited a dramatic increase in price due to an overall commodity boom during this period, but the changes were much more pronounced for some commodities than others. Throughout the period, several commodities feature short-term idiosyncratic movements. For example, the graph illustrates the upswing in Aluminum prices around 1986 resulting from a surge in global demand, followed by a plunge in prices in 1990 due to the supply influx coinciding with the dissolution of the Soviet Union (Plunkert and Jones, 1999).

\subsection{MSHA Mining Data}

We assembled a panel dataset containing quarterly employment, injuries, MSHA inspections, violations of MSHA regulations, corporate ownership, and other mine attributes from the Mine Safety and Health Administration's (MSHA's) open government data sets. ${ }^{11}$ The MSHA data cover each mine in the U.S. that contains statistical records related to mine health and safety standards. Beginning in 1983, each mine's operator is required by Title 30 Code of Federal Regulations Part 50 to report employment, accident, injury, illness, data to MSHA each quarter, if they occur (MSHA, 2016).

To prepare our data for estimation we merge five separate data sets provided by MSHA's open government data sets covering accidents, injuries, inspections, violations, production, and employment, resulting in a master panel dataset at the mine-quarter level spanning the period

\footnotetext{
${ }^{11}$ The datasets were downloaded from the MSHA website on September 2015, and can be accessed at the following link: https://enforcedata.dol.gov/views/data_summary.php
} 
1983-2015. Each data file has been treated as follows:

Mine Attributes: The Mine dataset lists all mines under MSHA's jurisdiction since 1970, including metals, non-metals, and other types of commodities. It includes such information as the current status of each mine (Active, Abandoned, NonProducing, etc.), the primary commodity that is mined, as well as a number of physical attributes of the mine, including mine type (Underground, Surface, Facility), longitude, latitude, and county. Also included is the mine's controller, or its ultimate corporate parent, as well as its operator, typically a subsidiary of the controller. We drop all mines that were abandoned prior to 1983, when the employment and accident data were first collected. We use a mine's primary commodity to merge in quarterly commodity price data for the 16 commodity series we assembled. Each mine has a unique Mine ID, which is used to link in our other datasets.

Quarterly Operator Employment. This dataset contains total employment and hours reported by mine operators in a given mine for each quarter in a calendar year, by subunit. The subunit code distinguishes between location and type of work being performed, including: (01) Underground; (02) Surface at underground; (03) Strip, quarry, open pit; (04) Auger; (05) Culm bank/refuse pile; (06) Dredge; (12) Other mining; (17) Independent shops or yards; (30) Mill operation/preparation plant; (99) Office workers at mine site. We collapse the subunits to create a measure of total employment and hours for each mine-quarter, as well as total employment excluding office workers, as office workers are the least likely to be at risk for workplace injuries. ${ }^{12}$

Injuries and Illnesses This dataset contains information on all accidents, injuries and illnesses reported by mine operators beginning with 1983, at the quarterly level. These data are obtained from the Mine Accident, Injury and Illness Report form (MSHA Form 7000-1) which operators are required by law to maintain. For each accident/injury/illness that is reported, the dataset includes information such as the subunit where the incident took place, the degree of the injury (e.g. a minor accident with no injury, resulted in restricted activity, days away from work, permanent disability, fatality), the source of the incident (e.g. due to handling of materials, a slip or fall, inhalation of dust, etc), and the date the incident was reported. The dataset includes other variables reported

\footnotetext{
${ }^{12}$ Roughly 10 percent of observations in our sample had zero overall employment in a quarter. These appear to either be instances in which a mine either temporarily halted operation and resumed at a later date, or instances in which a mine was about to shut down permanently but temporarily continued to report data to MSHA. We include these observations in our analysis, but all of our results are robust to dropping them.
} 
with varying frequency, such as the experience, tenure and occupation of the injured worker.

We collapse the dataset to get the total number, and various categories, of accidents and injuries by mine-quarter. These categories include injuries of varying severity, injuries to workers of different levels of tenure with the mine, and others that we primarily use in robustness checks. We then merge this dataset into the main analysis dataset, assigning zero to values that did not merge since it means that the mine did not have any accidents in that quarter. ${ }^{13}$

Inspections The Mine Inspections dataset includes details about every mine inspection MSHA has conducted since 1983. The data include MSHA's internal inspection number (event number), the start and end dates of the inspection, and the reason the inspection was initiated. The types of inspections we focus on in our analysis are "regular" inspections: according to the Mine Safety and Health Act, underground and surface mines are required to receive four and two regular inspections per year, respectively. We focus on these inspections because they occur at regular intervals and for reasons unrelated to events at the mine. Other types of inspections, such as spot inspections or technical inspections, can be initiated due to accidents or other events at the mine, and thus the occurrence of such inspections can itself be an endogenous outcome.

Violations This dataset contains information on each citation (if any) issued as a result of MSHA inspections, such as the date the violation was issued, and the specific MSHA standard that was violated, identified by the part and section number from Title 30 Code of Federal Regulations (CFR). Along with the standard that was violated, the dataset includes a measure of the inspector's assessment of the operator's negligence associated with the violation (categorized as reckless, high negligence, low negligence, moderate negligence, no negligence). A high degree of negligence is assigned when the operator was in a position to be aware of the condition that contributed to a dangerous situation and there were no mitigating circumstances, or if there are unique aggravating circumstances associated with the violation, such as repeated past violations of the same standard at the mine. We create a dummy equal to one for "High Negligence" violations to capture those for which fault most clearly lies (at least partially) with the operator, as opposed to the worker.

We collapse the Violations data down to the inspection level to create the number of total and various categories of violations cited in an inspection, which we merge into the Inspection dataset

\footnotetext{
${ }^{13}$ One limitation of our data on both injuries and illnesses, as well as employment and hours, is that we do not observe these measures for contract labor, which is used relatively frequently in this industry.
} 
via the event number. We keep only Regular inspections; the reason we do so is that we seek to have a measure of mines' compliance with safety regulations that is independent of their safety and health performance. Restricting to Regular Inspections only, we then collapse the data to the mine-quarter level, resulting in measures of the number of Regular inspections, and the number of various categories of violations cited at regular inspections, for each mine-quarter, which we merge into our master dataset by Mine ID/quarter.

Table 2 presents summary statistics on variables representing our primary outcome variables among the mines for which we have price data. ${ }^{14}$ Figure 2 illustrates where the mines in our sample are located: each U.S. county is assigned a color corresponding to the number of mines in our sample located in that county.

\section{$5 \quad$ Empirical Results}

\subsection{Effects of Price Shocks on the Extensive and Intensive Margin of Production}

We first test the effects of price shocks on the extensive margin of production. To do so, we model the number of mines that are in operation (Active) that mine commodity $j$ in quarter $t$ the following way:

$$
\log (\text { Active })_{j t}=\beta_{1} * \log (\text { price })_{j t-1}+\gamma_{j}+\theta_{y(t)}+\lambda_{q(t)}+\epsilon_{j t}
$$

where the log of the number of active mines is a function of the log of the global price of commodity $j$, lagged one quarter $\left(\log (\text { price })_{j t-1}\right)$, reflecting the mine's marginal value of production. ${ }^{15} \gamma_{j}$ captures any time-invariant features specific to mines in a particular commodity (e.g. the number of deposits of gold in the U.S. differs from the number of deposits of nickel) that could affect $Y$, and $\theta$ and $\lambda$ capture any year- or quarter-specific common shocks that affect all commodities equally. $\epsilon$ is an i.i.d. error term.

We estimate Equation 8 with a difference estimator to remove the unobserved commodity fixed

\footnotetext{
${ }^{14}$ We provide summary statistics for additional variables, discussed later in the text, in Table B.1.

${ }^{15}$ We include price lagged one quarter, rather than contemporaneous price, for the following reason: for most price series in our data, the price in quarter $t$ reflects the price at the end of the quarter, whereas our dependent variables (employment, injuries, etc) each reflect activity over the entire quarter, thus $Y_{t}$ measures outcomes that potentially took place before Price $_{t}$ is realized.
} 
effect $\gamma:^{16}$

$$
\Delta \log (\text { Active })_{j t}=\beta_{1} * \Delta \log (\text { price })_{j t-1}+\Delta \theta_{y(t)}+\Delta \lambda_{q(t)}+\Delta \epsilon_{j t},
$$

where $\Delta Y_{j t}=Y_{j t}-Y_{j t-\tau}$. In many instances, $\tau=1$, so that $\Delta$ indicates a one-quarter difference. However, we instead use $\tau=4$, so that $\Delta$ indicates a four-quarter difference. We do this primarily to remove seasonality effects. More mines may be active in the summer months than the fall or spring months due to temperature and other factors; using a 4-quarter difference holds such seasonality effects constant. We weight observations by the number of mines actively producing commodity $j$ four quarters prior (in $t-4$ ).

Because our key explanatory variable, Price, varies at the commodity level, it is appropriate to cluster our standard errors to allow for arbitrary correlation within commodities. As detailed in Abadie et al. (2017), clustering is appropriate when assignment to "treatment" is correlated within clusters. Here our "treatment" is a mine's quarterly commodity price. In a given quarter, all mines producing the same commodity have the same treatment, highlighting the need to cluster standard errors by commodity-quarter. Clustering more conservatively by commodity would be appropriate if "treatment" is correlated within commodities over time. If our treatment were at the level of commodity price, this would indeed be the case: the price of gold in spring 2005 is correlated with the price of gold in fall 2008. However, our specification is in first differences; the appropriate question is then whether the change in gold price spring 2004-spring 2005 is correlated with the change in gold pries fall 2007-fall 2008. If prices are a random walk, then this correlation will be zero. Indeed, in our 1983-2016 sample period, essentially none of the overall variance in $\Delta \log (\text { price })_{j t-1}$ is driven by within-commodity variance. Given this lack of correlation in price changes within commodities over time, we conclude that commodity-quarter is the appropriate level at which to cluster our standard errors. ${ }^{17}$

Our estimates of the effects of price changes on mine entry and exit are shown in Columns 1 and 2 of Table 4 . Column 1 reveals that a one-quarter lagged 1\% increase in price leads to a $0.09 \%$ increase in the number of mines actively producing $(p<.01)$. Column 2 includes one-, two-, three-, and four-quarter lags. The sum of these lags, representing the total effect of recent price changes

\footnotetext{
${ }^{16}$ Another approach to estimate Equation 8 would be with a fixed effects estimator. All of our point estimates are very similar under either specification.

${ }^{17}$ In robustness checks that we report below, we show that instead clustering by commodity yields very similar standard errors.
} 
on the number of active mines, is $0.17(p<.01)$. Positive price shocks, in other words, lead mines to increase production at the extensive margin.

To investigate the effects of price shocks on the intensive margin of production, we estimate a similar regression to Equation 8 but at the mine level, rather than the commodity level:

$$
\log (Y)_{i j t}=\beta_{1} * \log (\text { price })_{j t-1}+\gamma_{i}+\theta_{y(t)}+\lambda_{q(t)}+\epsilon_{i j t} .
$$

The variable $Y$ reflects inputs into production, which we operationalize as total number of workers or total hours worked. ${ }^{18}$ Here, $\gamma_{i}$ captures any time-invariant features specific to a particular mine (geology, capital configurations, management culture, etc) that could affect $Y$. As above, $\theta$ and $\lambda$ capture any year- or quarter-specific common shocks that affect all mines. $\epsilon$ is an i.i.d. error term.

As above, we estimate Equation 10 with a difference estimator:

$$
\Delta \log (Y)_{i j t}=\beta_{1} * \Delta \log (\text { price })_{j t-1}+\Delta \theta_{y(t)}+\Delta \lambda_{q(t)}+\Delta \epsilon_{i j t}
$$

By the same argument as above, we adjust standard errors to account for identical "treatment" within commodity-quarters. Since we also now include multiple observations for a given mine, we use two-way clustering by mine and commodity-quarter in all regressions at the mine-level and for which its own price is the key explanatory variable.

Columns 3-6 of Table 4 provides the results. A one-quarter lagged 1\% price increase leads to a $0.23 \%$ increase in employment $(p<.01)$, implying that the price elasticity of employment for the typical mine is 0.23 . The point estimate in Column 4 implies a price elasticity of total hours worked of 0.33 , suggesting that mines respond to price changes both by adjusting the number of workers, as well as the hours per worker. Including the four most recent lags (Columns 5-6) reveals an overall effect of recent price changes (given by the sum of the four lags) that for both employment and hours is roughly $50 \%$ larger in magnitude than the 1-quarter lagged price change alone. To ease exposition, the remainder of our results include only the log price change in the most recent quarter.

\footnotetext{
${ }^{18}$ To accommodate zeroes, we add the first percentile $(>0)$ before taking logs. Our results are insensitive to dropping observations with zero employment, as well as using the Inverse Hyperbolic Sine transformation instead of logs.
} 
While not the primary motivation of our paper, we note that our results on the price elasticity of employment provide a novel contribution to the extensive literature on labor demand. While classical labor demand theory highlights how labor demand is "derived demand" based on firms' product demand, we are unaware of any prior estimates of firms' output price elasticity of employment. This finding is related to other studies investigating how variation in rents from production affects labor demand (Kline et al., 2018), as well as changes in firms' product demand affects hiring (Garin and Silverio, 2017).

\subsection{Effects of Price Shocks on Workplace Safety}

Before estimating the causal effect of demand shocks on mines' rate of workplace injuries and illnesses, we first turn to the data to assess this relationship visually. Figure 3 plots the time series relationship between the quarterly price of various commodities in our sample and the mean number of injuries experienced among mines that produce them. To remove underlying time trends or shocks common to all commodities, we de-trend each variable by plotting the residual from separate regressions of a) quarterly commodity price, b) the number of accidents a mine experienced in a quarter, on year and quarter fixed effects. We also omit the years 2006-2015 since the boom and bust in commodity prices during these years skews the figures.

Figure 3 shows the four most common commodities in our sample: Copper, Silver, Gold, and Uranium. Two takeaways emerge from these figures. First, each of the four commodities exhibits different patterns in price series over time, highlighting the identifying variation in our data. Second, for each of the commodities there appears to be a positive relationship between changes in price and changes in the number of accidents experienced in its mines.

To statistically investigate the effects of price shocks on workplace safety and health outcomes, we estimate the regression corresponding to Equation 11 with dependent variables related to injuries. Results are shown in Table 5. In Column 1, the dependent variable is the log of the number of injuries and illnesses a mine experienced in a quarter. ${ }^{19}$ A one-quarter lagged $1 \%$ increase in price leads a mine to experience $0.14 \%$ more injuries and illnesses $(p<.01)$, implying that the price

\footnotetext{
${ }^{19}$ To accommodate zeroes, we add the first percentile $(>0)$ of each variable prior to logging it. We obtain essentially identical results if we instead use a Poisson specification or the inverse hyperbolic sine transformation to accommodate zeroes (reported in robustness checks below).
} 
elasticity of injuries is $0.14 .^{20}$

Of course, an increase in the number of injuries may reflect an increase in the risk that a given worker is injured at any given time, but it could also just reflect the increase in the number of hours worked (because an additional hour worked increases the chance an injury will occur). To isolate the former, Column 2 considers the effect of a price shock on the log number of injuries per 100 full time workers. ${ }^{21} \mathrm{~A}$ one-quarter lagged $1 \%$ price increase leads to a $0.15 \%$ increase in the $\log$ injury $\operatorname{rate}(p<.01)$, revealing that the increase in the number of injuries is not purely driven by the increase in hours.

These results imply that increases in output prices lead to a substantial increase in workers' risk of injury. However, another possibility is that price changes may affect workers' incentive to report injuries (Boone et al., 2011), rather than the actual occurrence of injuries. If workers perceive they are more likely to be fired after reporting an injury, they may be less willing to report an injury when the firm's output price is low (when the chance of being fired is higher), and more willing to report an injury when price is high. Thus, variation in reported injuries could reflect variation in reporting behavior, rather than the occurrence of true injuries.

To investigate whether the increase in injuries we observe in Columns 1 and 2 is driven by changes in reporting behavior, Columns 3 and 4 display results for types of injuries that are least likely to be subject to mis-reporting (Table B.1 provides descriptive statistics for these outcomes). In Column 3, the dependent variable is the number of traumatic injuries, which prior research has determined to typically be accurately reported (Morantz, 2013) ${ }^{22}$ The outcome in Column 4 is the number of injuries that are "severe" (where we define a "severe" injury as one that is fatal, results in a permanent disability, or results in days away from work), which constitute $38 \%$ of overall injuries in our sample. Prior research has shown that less-serious injuries are most prone to reporting bias (Biddle and Roberts, 2003; Boden et al., 2010), whereas the most serious injuries (such as death or permanent disability) are always reported.

\footnotetext{
${ }^{20}$ We obtain essentially identical estimates if we instead use the number of incidents leading to any injuries or illnesses, rather than the actual count of such injuries and illnesses.

${ }^{21}$ We calculate the number of full time workers as the number of hours worked divided by 500 (the number of hours a worker working 40 hours per week would work in a quarter), adding the first non-zero percentile of hours to the denominator to smooth out effects from small outliers.

${ }^{22}$ Because traumatic injuries are sustained by a worker due to a discrete event at work, its work-relatedness is rarely in dispute, such that workers are less likely to under-report them. We follow the rules used in Morantz (2013) to characterize injuries that are traumatic based on the nature of the injury.
} 
Columns 3 and 4 of Table 5 reveal a price shock leads to an increase in both of these categories of injuries, suggesting the relationship between prices and injuries is not purely a function of changes in workers' reporting behavior.

Because the MSHA data include rich information about the details of each injury, including the specific circumstance or incident that caused it, as well as the source of the injury (e.g. the object, substance, or bodily motion that produced it), we can investigate whether price shocks affect particular types of injuries. For example, as workers work longer hours, their risk of injury could increases due to over-work, exhaustion and over-exertion (Halbesleben, 2010). Alternatively, mine owners may be less willing to replace old equipment or halt production for maintenance of machinery when prices are high, so that high prices could lead to an increase in injuries involving contact with machinery. If high prices lead to an increase in overall activity, this could increase the likelihood that a worker is struck by a moving, falling, or flying object.

Table B.2 investigates how price shocks affects injuries driven by various circumstances or objects. We consider four of the most frequent circumstances that lead to injuries in the MSHA data-a) worker over-exertion, b) "struck-by" injuries (i.e. a worker being struck by a moving object), c) injuries caused by contact with machinery, and d) injuries resulting from a worker falling. The table reveals that all four of these types of injuries increase following a positive price shock. One implication of this table's results is that the injuries that are affected by demand conditions are not purely due to workers working longer hours, or excess workers leading to overcrowding of the work space and making injuries more likely. Rather, injuries such as those resulting from a worker falling, or from contact with machinery, likely arise due to lack of precaution, proper equipment, proper maintenance, or training that reflect general investments in safety.

In summary, these results indicate that advantageous demand conditions lead to a substantial increase in workers' risk of injury, that this relationship reflect a real deterioration in workplace safety rather than changes in reporting behavior, and that the effects are not confined to a narrow class or source of injuries.

\subsubsection{The Role of Changing Worker Composition}

Given the theoretical framework in Section 2, the results above imply that the "opportunity cost"

effect of demand shocks on workplace safety outweigh their "income," or liquidity, effect of easing 
financial constraints on safety investments. However, there are other reasons outside of our model that price shocks could affect mines' injury rates. We assess these alternative explanations in this section.

One potential channel besides the two our model emphasizes is that price shocks might affect the composition of a mine's workers. The likelihood of an occupational injury decreases with worker tenure and experience (Breslin and Smith, 2006; Bena et al., 2013), and if firms increase hiring in booms then the average tenure of their workforce would decline as price rises. Thus, a firm may experience more injuries during advantageous demand conditions purely because it has more inexperienced workers. An additional channel is that mines may hire independent contractors to work on a short-term basis during times of high prices. Contractor workers may be more prone to injury (Buessing and Boden, 2016). ${ }^{23}$

Table 6 investigates the role of changes in worker composition. We leverage details that mines must report for each injury that occurs in a quarter, such as the injured worker's tenure with the mine and experience in the mining industry, as well as whether the incident that led to the injury involved a contract worker.

Column 1 reproduces the baseline result on $\log$ of the number of overall injuries for reference. Columns 2-4 report the effects on the number of injuries among workers with less than 6 months experience at the mine, among those with more than 6 months experience, and among those whose experience is not reported in the MSHA data. The results reveal that the number of injuries among workers with less than 6 months of tenure increase by $15 \%(p<.01)$, consistent with the proportion of such workers increasing following a price shock. However, injuries among workers with more than 6 months of tenure, or with their tenure not recorded, also increase by roughly $5 \%$ each. These results show that the overall increase in injuries is not solely an artifact of injuries among inexperienced workers.

Columns 5-6 use as the dependent variable the number of incidents that do and do not involve an independent contractor. Both types of incidents yield similar results, suggesting that the changing use of contract labor does not fully explain our results.

In short, our results suggest that price shocks have a statistically significant and economically

\footnotetext{
${ }^{23}$ Additionally, while injuries involving contractors show up in our injury data, our data on annual mine employment do not include use of contract labor; if a large portion of injuries involve contractors then our measure of injury rate would be too high since the denominator is too small.
} 
meaningful effect on the rate of workplace injuries, and that this effect is not purely driven by changes to the composition of the workforce, or changes in workers' reporting incentives.

\subsection{Robustness Tests}

Table 7 reports various tests to assess the robustness of our main results. Column 1 reports our baseline estimate of the effect of price shocks on the number of injuries experienced in a mine. In Column 2, we take a more conservative approach to inference and cluster our standard errors by commodity, rather than two-way clustering by commodity-quarter and mine. Because we have only 16 commodities, the asymptotic properties of traditional cluster-robust errors are unlikely to hold. Thus, we use the wild bootstrap procedure from Cameron et al. (2008). The standard error increases only slightly, and the coefficient remains highly statistically significant; the small size of the change is consistent with the idea that price shocks within commodities over time are uncorrelated.

Columns 3-5 assess the sensitivity of our estimates to our chosen functional form: OLS firstdifference. In Column 3, we use the Inverse Hyperbolic Sine (IHS) transformation, rather than $\log$, to transform our dependent variable. The IHS is increasingly seen as an alternative to the log transformation in the presence of zero values (Bellemare and Wichman, 2018). In Column 4, we use an OLS fixed effects specification, akin to Equation 10 instead of first-difference. In Column 5, we use a conditional fixed effects Poisson regression; because \# Injuries is a count variable, a Poisson regression is in theory a more appropriate specification. In each case, the estimate of the effect of the price remains essentially unchanged.

While most of our estimates thus far use the commodity price from the most recent quarter as the key explanatory variable, including the effects of leading prices, as well as more distant lags, is informative about the reliability of our results. Leading prices (commodity prices in future quarters) should have zero effect on mines' decision-making today; if we found an effect of leading price, we would be worried we are picking up a spurious effect.

Estimating the effects of earlier lags is also informative. Conditional on current price, price from earlier years should have little effect on injuries today. In theory, we might even expect past prices to have an opposite-signed effect on today's injuries, compared to today's price. For example, if high prices in the past relaxed financial constraints and led a mine to increase safety 
investments, the positive effects of these investments on safety could persist to present day, whereas the substitution effect (prices affecting the opportunity cost of spending on safety) has passed.

Figure 4 displays coefficients and confidence intervals from an amended version of Equation 11 that includes price lagged 1, 5, and 9 quarters, as well as price leading 1, 5, and 9 quarters. Encouragingly, all leads are basically zero, as are the early lags. The coefficient on price lagged one quarter $(0.15, p<.01)$ is very similar to the coefficient obtained without including the leads and earlier lags.

\subsection{Price Shocks and Compliance with Safety and Health Regulations}

The results reported in the previous section provide consistent evidence that changes in output prices affect the number and rate of injuries and illnesses that workers experience. This evidence suggests that demand shocks affect mines' opportunity cost of spending resources on worker safety. One way to measure mines' investment in and monitoring of safety is their compliance with safety and health regulatory standards. In this section, we investigate whether changes in mines' output price affects their compliance with MSHA regulations.

To measure compliance with MSHA regulations, we use violations of MSHA safety and health standards cited in inspections of a mine throughout the quarter. We restrict to violations observed in "Regular" MSHA inspections, which are routine inspections that MSHA is required to regularly conduct of all operating mines. Restricting to such inspections ensures that we do not run the risk of selection bias that can arise from using outcomes observed conditional on an endogenous event that would trigger other types of inspections. MSHA rules, each mine is supposed to get a routine inspection at least once a year. However, the exact timing of these inspections may vary year to year. Some years, a mine may be inspected in Q1, other years in Q3, etc. This erratic timing means that our first-difference specification will lose data, since we do not always observe violations 4 quarters apart.

To address this issue, we use a "pseudo" first-difference specification, in which the dependent variable is

$$
\text { Average }\left(\text { Viols }_{t-1}, \text { Viols }_{t}, \text { Viols }_{t+1}\right)-\operatorname{Average}\left(\operatorname{Viols}_{t-5}, \text { Viols }_{t-4}, \text { Viols }_{t-3}\right) \text {, }
$$


where Average $\left(\right.$ Viols $_{t-1}$, Viols $_{t}$, Viols $\left._{t+1}\right)$ is the mean number of violations found during inspections conducted during quarters $t-1, t$, and $t+1$. We measure Price analogously. ${ }^{24}$

Table 8 displays the estimated effect on compliance. ${ }^{25}$ The estimate in Column (1) implies that a $1 \%$ increase in a mine's commodity price leads to $13 \%$ more violations of MSHA regulations detected during routine MSHA inspections $(p<.01)$. This estimate is consistent with the idea that higher outpout prices raise the opportunity cost of inputs into worker safety. However, in theory compliance with safety regulations can reflect the priorities and decisions of both managers and workers, as well as various extenuating circumstances. To isolate violations that reflect willful managerial decisions, Column (2) uses the number of violations the MSHA inspector deems to be "high negligence." According to MSHA documentation, "A high degree of negligence is assigned when the operator was in a position to be aware of the condition that contributed to a dangerous situation and there were no mitigating circumstances." 26 The estimate reported in Column (2) implies that a $1 \%$ price increase leads to a $6 \%$ increase in High-Negligence Violations, suggesting that variation in output prices shifts managerial priorities. Overall, these findings further indicate that mines invest less in safety when experiencing positive demand shocks.

\subsection{Heterogeneous Responses at Surface vs Underground Mines}

We have noted important differences between surface and underground mines that may differentially affect their responsiveness to demand shocks. As discussed in section 3.3, surface mines face limits on their ability to expand output while underground have more flexibility to do so. Moreover, the marginal unit of production is likely more risky at underground mines than surface mines, for example due to unstable ground control conditions more salient underground. Thus, we not only anticipate that underground mines will be more responsive to price shocks than surface mines, but that these responses will be associated with higher rates of injuries and illnesses. In this section we test for such heterogeneity, given that it is a direct prediction of our model and features of the industry.

\footnotetext{
${ }^{24}$ We obtain essentially identical point estimates, but with reduced sample size and precision, when we use an unadjusted first-difference specification.

${ }^{25}$ Note that the footer of Table 8 indicates that our regressions have 29,359 observations, even though Table 2 indicated that we have 21,480 observations with non-missing values of violations. This discrepancy arises because of the approach we take to use violations averaged across quarters, described in the preceding paragraph, which expands the number of observations we have for this analysis.

${ }^{26}$ MSHA data dictionary, available at the link in Footnote 11
} 
Table 9 presents results on the effects of price shocks on employment, hours, injuries, and violations, in which we also include an interaction between the price shock measure and a binary indicator equal to one if the mine is underground. Thus, we interpret the coefficient on the main effect of price shock as the impact on surface mines while the coefficient on the interaction term is the difference in the response between underground and surface mines.

The findings in Table 9 are consistent with the predictions discussed above. As shown in column (1), in spite of the pit limits, we find that employment in surface mines responds significantly to demand shocks. However, employment is twice as responsive at underground mines to a shock of the same magnitude and this difference in the response is statistically significant. We find that hours worked also are more responsive at underground mines (Column (2)) by roughly the same magnitude, although the difference is only marginally significant. Also consistent with our discussion that underground mines face riskier marginal units of production than do surface mines, in column (3) of Table 9 we find a larger increase in injuries and illnesses at underground mines relative to surface mines although this differences is marginally significant. As shown in the final column of the Table, we are unable reject that null hypothesis that safety violations respond the same across the two types of mines although the point estimates is somewhat larger for underground mines.

\section{Isolating the Effects of Financial Resources on Safety}

The framework in Section 2 illustrates how a price change has two offsetting effects on workplace injuries, on one hand increasing injuries (raising the opportunity cost of safety investments like training that crowd out production), and on the other hand decreasing injuries (by relaxing financial constraints that otherwise limit valuable safety investments). Our results above imply that the former channel dominates. However, these results do not imply that cash flow and other financial constraints are unimportant to firms' safety and health outcomes. Indeed, Cohn and Wardlaw (2016) find that financially constrained firms have significantly higher injury rates, and Rose (1990a) and Asfaw et al. (2013) find that firms' accidents and injuries decrease when they are more profitable. Positive price shocks could be relaxing these constraints, but this effect may just be outweighed by the opportunity cost channel. To gauge the extent to which cash flow constraints 
limit firms' safety and health investments, and whether price shocks relax them, we need a situation in which changes in commodity prices affect mines' cash flow without affecting their opportunity cost of safety.

To identify such a situation, we rely on mines' internal corporate networks. Cash flow shocks to one establishment in a multi-unit firm often get transferred to other establishments within the firm via the corporate parent (Williamson, 1975; Giroud and Mueller, 2017); in this spirit, prior research has shown investment by establishments owned by a corporate parent that also owns an oil and gas company declined when oil prices decreased dramatically in 1986 (Lamont, 1997). Building from this logic, Cohn and Wardlaw (2016) find that injury rates in establishments with a corporate sibling in oil and gas are sensitive to oil prices.

Applying the insight from this prior research, we examine how a mine's injury rate is affected by price shocks to commodities produced by other mines owned by its corporate parent (its "corporate siblings"). For example, consider a gold mine that is owned by a corporate parent that also owns a silver mine. If the price of silver increases, this provides the gold mine, via its internal corporate network, a positive cash flow shock. As illustrated in our model in Section 2, a "pure" cash flow shock like this has no effect on the mine's opportunity cost of safety inputs. Thus, holding own price constant, a mine's injury rate should unambiguously should go down following a positive price shock to commodities produced by its corporate siblings.

To test this hypothesis, we restrict the sample to mines that are part of multi-unit firms. $70 \%$ of the observations (and $60 \%$ of the mines) in our sample are in multi-unit firms, and just under half of these are in firms that own a mine that produces a different commodity for which we have price data. We estimate the following equation:

$\Delta \log (\text { InjuryRate })_{i, t}=\beta_{1} * \Delta \log (\text { price })_{k, t-1}+\beta_{2} \sum_{l \neq k} \omega_{j, k, l} \Delta \log (\text { price })_{l, t-1}+\Delta \theta_{y(t)}+\Delta \lambda_{q(t)}+\Delta \epsilon_{i k t}$

Here, $\beta_{1}$ estimates, for mine $i$ that produces commodity $k$ the effect of an own-price shock on a mine's log injury rate in quarter $t$, comparable to the results reported previously. The new term $\sum_{l \neq k} \omega_{j, k, l} \Delta \log (\text { price })_{l, t-1}$ is a weighted average percentage change in prices of other commodities $(l \neq k)$. The weight $\omega$ given to commodity $l$ for mine $i$ that produces commodity $k$ and which is part of firm $j$ corresponds to the employment-weighted share of a mine $i$ 's corporate siblings that 
produce commodity $l$ :

$$
\omega_{j, k, l}=\frac{E m p_{j, l}}{\sum_{m} E m p_{j, m}},
$$

where the denominator is summed over the total employment from all commodities $m$ produced by firm $j$ 's internal corporate network. Consider a mine that produces commodity $k$ and that is owned by corporate parent $j$. If $j$ owns no other mines that produce commodity $l$, then commodity $l$ gets zero weight. If its parent $j$ does own at least one other mine that produces $l$, then $l$ is given positive weight, and this weight increases when the firm's total employment in mines producing $l$ is larger as a share of its total employment. ${ }^{27}$ Given this structure, $\beta_{2}$ estimates the effect of changes in price of commodities produced by a mine's corporate siblings, isolating a shock to a mine's cash flow that holds constant its opportunity cost of safety inputs. Standard errors are clustered by firm.

We report results in Table 10. Column 1 reproduces the estimates of the own-price elasticity of a mine's injuries (the percent change in its injury count following a one percent change in the price of the commodity it produces) for the set of mines in our main analysis sample. ${ }^{28}$ In Column 2 , we restrict the sample to mines with at least one corporate sibling that produces a different commodity for which we have price data: we lose roughly $75 \%$ of our observations, but the estimated elasticity stays qualitatively similar $(0.118)$ and is highly significant $(p<.01)$. In Column 3 , we add in the corporate sibling-weighted average price change. First, the own-price elasticity remains unchanged. Second, the coefficient on the corporate sibling average price change implies that a one percent increase in the weighted-average price of commodities produced by a mine's siblings leads to a 0.021 percent decline in its injury rate $(p<.01)$.

The estimate in Column 3 is consistent with price shocks affecting cash flow constraints on investments in worker safety, holding constant their effect on opportunity costs. However, this estimate could in theory be muddied if firms shift workers across mines facing differential demand shocks. In Column 4, we address this concern by calculating the average price of a mine's corporate siblings located in different counties, since firms would be less likely to transfer workers across mines

\footnotetext{
${ }^{27}$ This specification is similar to Giroud and Mueller (2017), who study how establishments' employment is affected by changes in house prices in zipcodes where its corporate siblings are located during the Great Recession.

${ }^{28}$ For internal consistency in this table, this specification in Column 1 clusters standard errors by firm, rather than by mine as done in previous specifications. We note that the standard error is essentially unchanged.
} 
located further away. ${ }^{29}$ The estimate is very similar and, if anything, slightly larger in magnitude $(-0.023, p \leq .01)$.

Another concern behind the estimates in Columns 3 and 4 is that variation in the prices of commodities produced by a mine's corporate siblings could reflect how a mine's behavior changes in response to demand for substitutable products, rather than any effect they might have on its cash flow. To ensure that such confounding effects are not driving the relationship we observe in Column 3, in Columns 5 and 6 we instead include the log price of a randomly selected commodity that is not produced by any mine in a mine's firm. Reassuringly, whether we use our restricted sample of mines with a corporate sibling that produces a different commodity (Column 5) or the entire sample (Column 6), the estimate on this term is essentially equal to zero and nowhere near statistically significant.

These results corroborate the predictions of our model: while a price shock has a theoretically ambiguous effect on worker safety, positive shocks to cash flow unambiguously lead to improved safety outcomes. Furthermore, they reconcile our earlier findings with prior literature that has highlighted how establishments' safety investments are limited by the financial resources at their disposal. Changes in the demand for an establishment's product is an important driver of its financial resources, and the results in this section illustrate that positive demand shocks do lower injuries, via their effect on cash flow. However, this effect is clearly dominated by the effect of demand shocks on the opportunity cost of safety inputs. Financial constraints very likely limit firms' investments in safety inputs, but factors that alleviate these constraints may also reduce firms' incentives to make these investments. While overlooked in prior literature, this latter effect can have an economically meaningful effect on workplace injuries and illnesses.

\section{Conclusion}

We examine how output demand shocks affect employers' provision of safety. Economic theory yields an ambiguous prediction regarding this relationship: on the one hand, a positive demand shock will lower safety due to the opportunity cost regarding increased production while on the

\footnotetext{
${ }^{29}$ Of the mines that are in firms that also own a different-commodity mine in the same quarter, roughly 9 percent have no different-commodity corporate siblings in a different county. These observations thus do not account for any of the variation in Column 4.
} 
other hand such a shock can loosen credit constraints and generate increased investment in safety. Focusing on the US metals mining sector and using short-term variation in global commodity prices as a measure of demand shocks, we find that injuries and illnesses and safety regulation noncompliance all increase when mines experience positive demand shocks. These results indicate that, on net, the opportunity cost channel dominates the response of safety provision to demand shocks. However, leveraging mines' internal corporate networks, we find that greater financial resources do improve safety, holding opportunity costs constant.

Ensuring safe and healthy working conditions requires investments by firms in both financial resources and time. A small literature finds that firms face real constraints in making these investments, i.e. that limited cash flow and other financial frictions increase the prevalence of workplace injuries and illnesses. We find that one of the most salient factors that can relieve firms' cash flow constraints - increased demand for their product - actually increases injuries. Combined with our theoretical framework, our results highlight that changes in demand also affect firms' opportunity costs of safety investments that come at the expense of short-term production.

Our findings have several broad implications. First, they inform scholars' understanding of how firms respond to demand shocks. A long literature has investigated how firms adjust wages and employment in response to idiosyncratic- and market-level demand shocks. Our results imply that any conclusion that researchers draw from this relationship must account for the possibility that workers' safety is changing at the same time. Thus, for example, any indication that wages do adjust to demand shocks, which could be interpreted as profit-sharing, may reflect compensating differentials for changes in injury risk. Alternatively, if wages do not adjust to demand shocks, which could be interpreted as firms insuring workers against wage loss, may miss the fact that overall compensation is in fact changing.

Our results also have implications for the design of workplace safety and health regulations. Whereas the frequency of audit inspections and the severity of financial penalties is invariant to firms' economic position, it may be optimal for regulators to consider policies that vary the severity of enforcement with the demand for firms output. 


\section{References}

Abadie, Alberto, Susan Athey, Guido W Imbens, and Jeffrey Wooldridge, "When should you adjust standard errors for clustering?," Technical Report, National Bureau of Economic Research 2017.

Abowd, John A and Thomas Lemieux, "The effects of product market competition on collective bargaining agreements: The case of foreign competition in Canada," The Quarterly Journal of Economics, 1993, 108 (4), 983-1014.

Anderson, Soren T, Ryan Kellogg, and Stephen W Salant, "Hotelling under pressure," Journal of Political Economy, 2018, 126 (3), 984-1026.

Asfaw, Abay, Christopher Mark, and Regina Pana-Cryan, "Profitability and occupational injuries in US underground coal mines," Accident Analysis $\&$ Prevention, 2013, 50, 778-786.

Atkin, David, Amit K Khandelwal, and Adam Osman, "Exporting and firm performance: Evidence from a randomized experiment," The Quarterly Journal of Economics, 2017, 132 (2), $551-615$.

Beauchamp, L, "Ground control in underground mines," Stellman JM, McCann M, Warshaw L, et al, 1998, pp. 28-74.

Bellemare, Marc F and Casey J Wichman, "Elasticities and the inverse hyperbolic sine transformation," Technical Report, Working Paper. University of Minnesota 2018.

Bena, Antonella, Massimiliano Giraudo, Roberto Leombruni, and Giuseppe Costa, "Job tenure and work injuries: a multivariate analysis of the relation with previous experience and differences by age," BMC public health, 2013, 13 (1), 869.

Biddle, Jeff and Karen Roberts, "Claiming behavior in workers' compensation," Journal of Risk and Insurance, 2003, 70 (4), 759-780.

Boden, Leslie I, Nicole Nestoriak, and Brooks Pierce, "Using Capture-Recapture Analysis to Identify Factors Associated with Differential Reporting of Workplace Injuries and Illnesses October," 2010. 
Boone, Jan, Jan C van Ours, Jean-Philippe Wuellrich, and Josef Zweimüller, "Recessions are bad for workplace safety," Journal of health economics, 2011, 30 (4), 764-773.

Breslin, F Curtis and Peter Smith, "Trial by fire: a multivariate examination of the relation between job tenure and work injuries," Occupational and Environmental Medicine, 2006, 63 (1), $27-32$.

Buessing, Marric and Leslie I Boden, "The impact of contract operations on safety in underground coal mines," Journal of occupational and environmental medicine, 2016, 58 (9), 952-956.

Cameron, A Colin, Jonah B Gelbach, and Douglas L Miller, "Bootstrap-based improvements for inference with clustered errors," The Review of Economics and Statistics, 2008, 90 (3), $414-427$.

Caskey, Judson and N Bugra Ozel, "Earnings expectations and employee safety," Journal of Accounting and Economics, 2017, 63 (1), 121-141.

Chambers, Matt, "Tropicana looking good as AngloGold itches to go," The Australian, Aug 2009.

Chen, Xun Yao, "A must-know overview of the US thermal coal industry for investors PART 4 of 12: Why underground mines cost higher compared to surface coal mines," Market Realist, Apr 2014.

Cohn, Jonathan B and Malcolm I Wardlaw, "Financing constraints and workplace safety," The Journal of Finance, 2016, 71 (5), 2017-2058.

Dembe, Allard E, J Bianca Erickson, Rachel G Delbos, and Steven M Banks, "The impact of overtime and long work hours on occupational injuries and illnesses: new evidence from the United States," Occupational and environmental medicine, 2005, 62 (9), 588-597.

Dworsky, Michael, Stephanie Rennane, and Nicholas Broten, "Wage Loss Monitoring for Injured Workers in California's Workers' Compensation System," 2018. 
Ellerman, Denny, Thomas Stoker, and Ernst R Berndt, "Sources of productivity growth in the American coal industry 1972-95," in "New developments in productivity analysis," University of Chicago Press, 2001, pp. 373-418.

Ferraz, Claudio, Frederico Finan, and Dimitri Szerman, "Procuring firm growth: the effects of government purchases on firm dynamics," Technical Report, National Bureau of Economic Research 2015.

Fishback, Price V, "Liability rules and accident prevention in the workplace: empirical evidence from the early twentieth century," The journal of legal studies, 1987, 16 (2), 305-328.

Garin, Andrew and Filipe Silverio, "How Does Firm Performance Affect Wages? Evidence from Idiosyncratic Export Shocks," Technical Report, Working Paper 2017.

Giroud, Xavier and Holger M Mueller, "Firms' Internal Networks and Local Economic Shocks," Technical Report, National Bureau of Economic Research 2017.

Gowrisankaran, Gautam, Charles He, Eric A Lutz, and Jefferey L Burgess, "Productivity, safety, and regulation in underground coal mining: Evidence from disasters and fatalities," Technical Report, National Bureau of Economic Research 2015.

Greenstone, Michael, John A List, and Chad Syverson, "The effects of environmental regulation on the competitiveness of US manufacturing," Technical Report, National Bureau of Economic Research 2012.

Greenwood, Robin and Samuel G Hanson, "Waves in ship prices and investment," The Quarterly Journal of Economics, 2014, 130 (1), 55-109.

Halbesleben, Jonathon RB, "The role of exhaustion and workarounds in predicting occupational injuries: A cross-lagged panel study of health care professionals.," Journal of occupational health psychology, 2010, 15 (1), 1.

Harvey, Curtis, The Economics of Kentucky Coal, University Press of Kentucky, 2015. 
Hummels, David, Jakob Munch, and Chong Xiang, "No Pain, No Gain: The Effects of Exports on Effort, Injury, and Illness," Technical Report, National Bureau of Economic Research 2016.

IGO, "Creating a Leading Diversified Mining Company," Company Annual Report, Independence Group NL (IGO) 2015.

Kline, Patrick, Neviana Petkova, Heidi Williams, and Owen Zidar, "Who profits from patents? rent-sharing at innovative firms," Technical Report, National Bureau of Economic Research 2018.

Kniesner, Thomas J and John D Leeth, "Regulating occupational and product risks," in "Handbook of the Economics of Risk and Uncertainty," Vol. 1, Elsevier, 2014, pp. 493-600.

Krueger, Alan B, "Incentive effects of workers' compensation insurance," Journal of Public Economics, 1990, 41 (1), 73-99.

Lamont, Owen, "Cash flow and investment: Evidence from internal capital markets," The Journal of Finance, 1997, 52 (1), 83-109.

Leigh, J. Paul, "Economic burden of occupational injury and illness in the United States," The Milbank Quarterly, 2011, 89 (4), 728-772.

Levine, David I, Michael W Toffel, and Matthew S Johnson, "Randomized government safety inspections reduce worker injuries with no detectable job loss," Science, 2012, 336 (6083), 907-911.

Li, Ling and Perry Singleton, "The effect of workplace inspections on worker safety," ILR Review, 2019, 72 (3), 718-748.

Maestas, Nicole, K Mullen, David Powell, T von Wachter, and J Wenger, Working Conditions in the United States: Results of the 2015 American Working Conditions Survey, RAND, 2017. 
Moore, Michael J and W Kip Viscusi, "Promoting safety through workers' compensation: The efficacy and net wage costs of injury insurance," The RAND Journal of Economics, 1989, pp. 499-515.

Morantz, Alison D., "Coal Mine Safety: Do Unions Make a Difference?," ILR Review, 2013, 66 (1), 88-116.

MSHA, "Title 30 Code of Federal Regulations, Parts 1-199: Mineral Resources," 2016.

National Safety Council, "The Business Case for Investments in Safety-A Guide for Executives," Technical Report 2013.

Newman, Alexandra M, Enrique Rubio, Rodrigo Caro, Andrés Weintraub, and Kelly Eurek, "A review of operations research in mine planning," Interfaces, 2010, 40 (3), 222-245.

Organization, International Labour, "Safety \& health in underground coal mines: a code of practice," Technical Report 2006.

Plunkert, Patricia A. and Thomas S. Jones, "Metal Prices in the United States Through 1998,” Technical Report, U.S. Department of the Interior, U.S. Geological Survey 1999.

Popescu, Dan, "Supply, Demand, the Stock of Gold and their Impact on Price," Jan 2014.

Rockoff, Hugh, "Some evidence on the real price of gold, its costs of production, and commodity prices," in "A Retrospective on the Classical Gold Standard, 1821-1931," University of Chicago Press, 1984, pp. 613-650.

Rose, Nancy L, "Profitability and product quality: economic determinants of airline safety performance," Journal of Political Economy, 1990, 98 (5, Part 1), 944-964.

Rose, Nancy L., "Profitability and Product Quality: Economic Determinants of Airline Safety Performance," Journal of Political Economy, 1990, 98 (5), 944-964.

Rosen, Sherwin, "The theory of equalizing differences," Handbook of labor economics, 1986, 1, 641-692.

Ruhm, Christopher J, "Are recessions good for your health?," The Quarterly journal of economics, 2000, 115 (2), 617-650. 
Ruser, John, Richard Butler et al., "The economics of occupational safety and health," Foundations and Trends® in Microeconomics, 2010, 5 (5), 301-354.

Ruser, John W, "Workers' compensation and occupational injuries and illnesses," Journal of Labor Economics, 1991, 9 (4), 325-350.

_ , "Self-correction versus persistence of establishment injury rates," Journal of Risk and Insurance, 1995, pp. 67-93.

Thomason, Terry and Silvana Pozzebon, "Determinants of firm workplace health and safety and claims management practices," ILR Review, 2002, 55 (2), 286-307.

Walle, Manfred, Norman Jennings et al., "Safety \& health in small-scale surface mines: a handbook," Technical Report, International Labour Organization 2001.

Williamson, Oliver E, "Markets and hierarchies," New York, 1975, 2630. 


\section{Tables and Figures}

Figure 1: Standardized Commodity Prices 1983-2015.

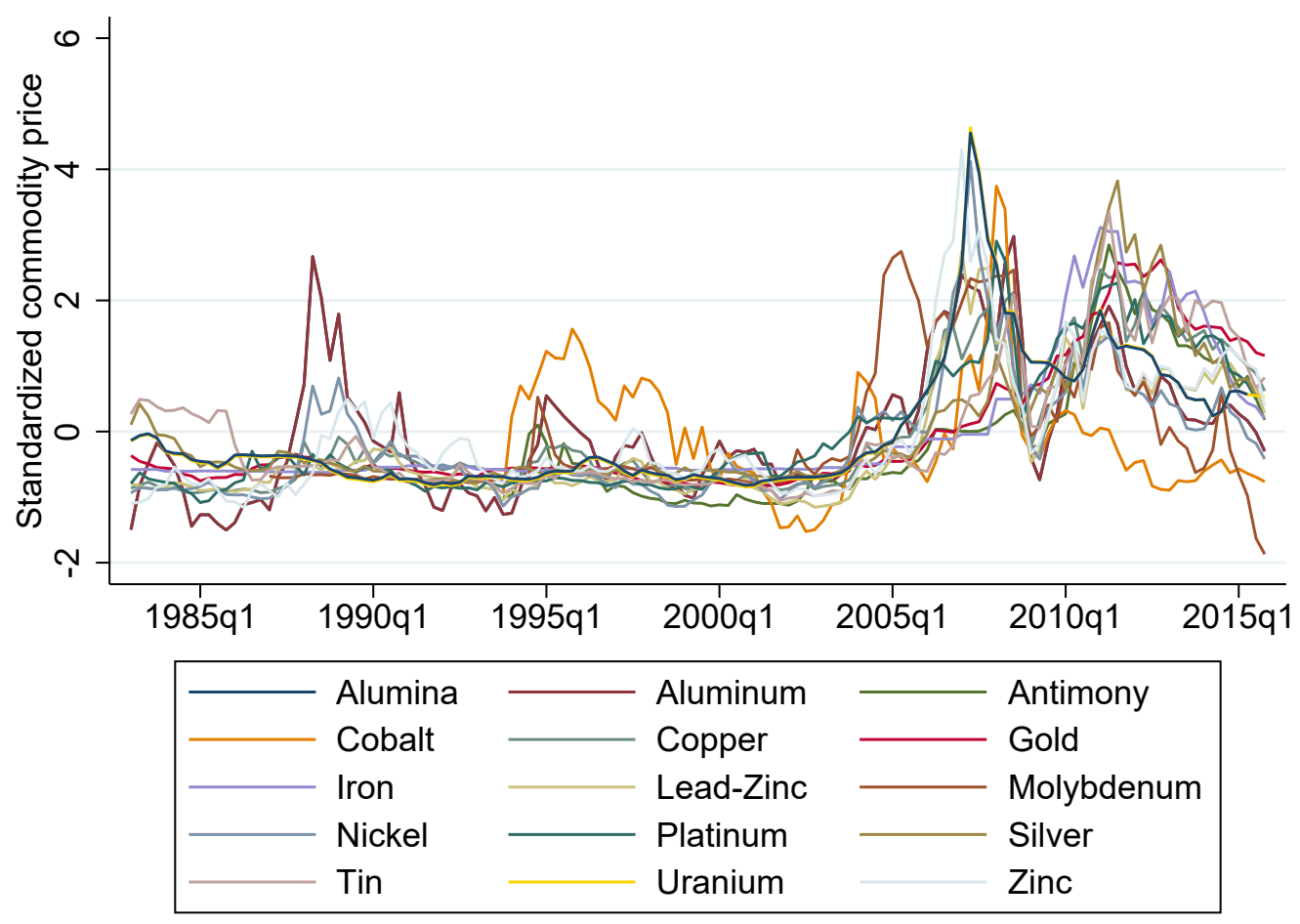

Notes: The standardized price nets out the commodity-specific mean and is scaled by the commodity-specific standard deviation. The figure includes 15 of the 16 commodities in our sample (Uranium-Vanadium is not included). 
Figure 2: Location of Mines in our sample.

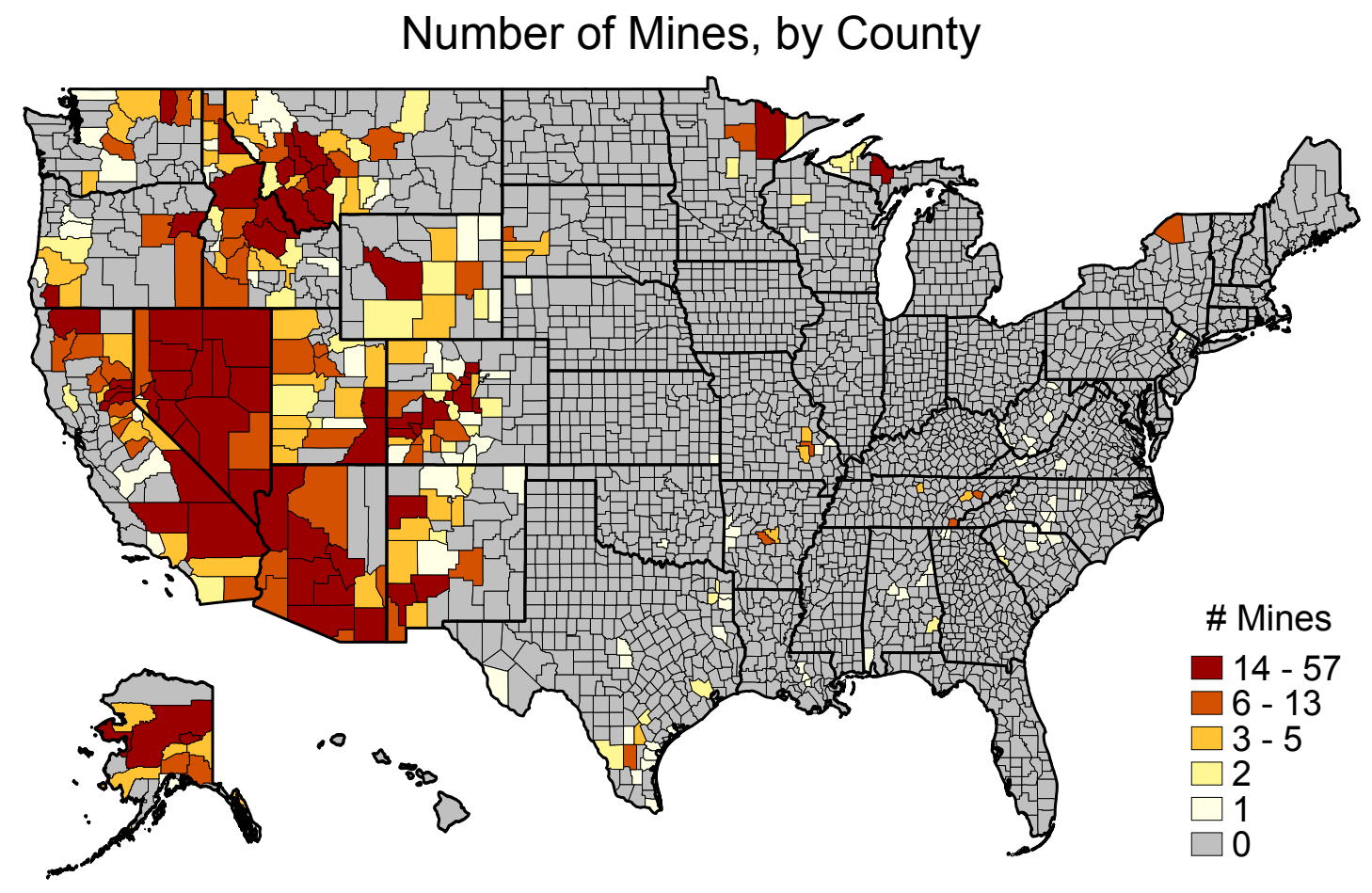

Notes: The figure represents the number of mines in our sample period. 
Figure 3: The Time-Series Relationship Between Commodity Prices and the Number of Workplace Injuries in Mines that Produce Them
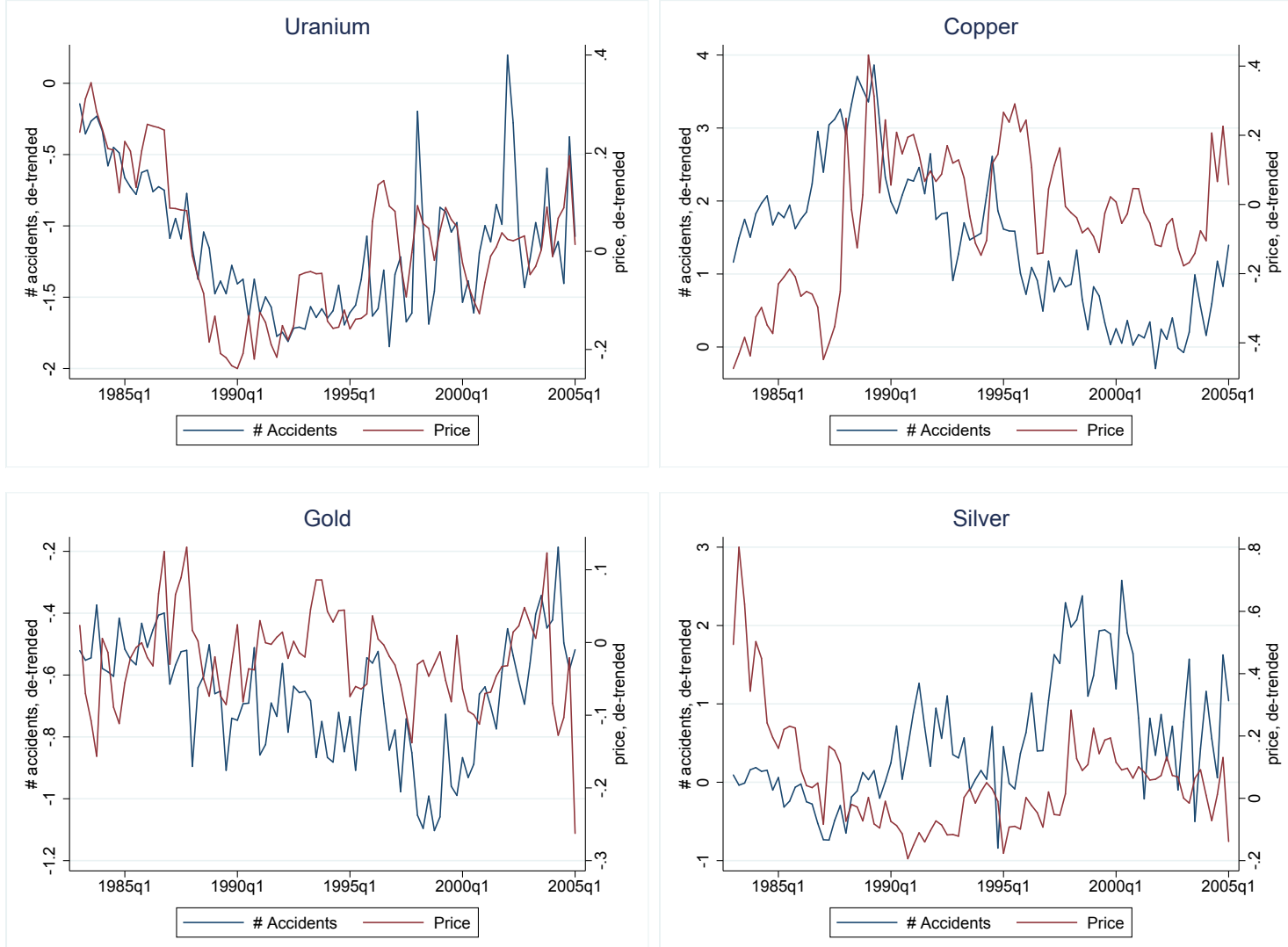

Notes: The figures plot de-trended time series of commodities' quarterly price, and the average number of injuries experienced in a quarter among mines that produce them, over the period 1983-2005 (we omit the years 2006-2014 due to the dramatic boom and bust in prices these years that would render these graphs difficult to interpret). Price and injuries are de-trended by regressing the corresponding variable on year and quarter fixed effects, and then keeping the residual. \# Injuries is then calculated as the mean number of (de-trended) injuries among all mines actively producing the commodity that quarter. 
Figure 4: Effects of Leading and Lagged Commodity Prices on Injury Rates

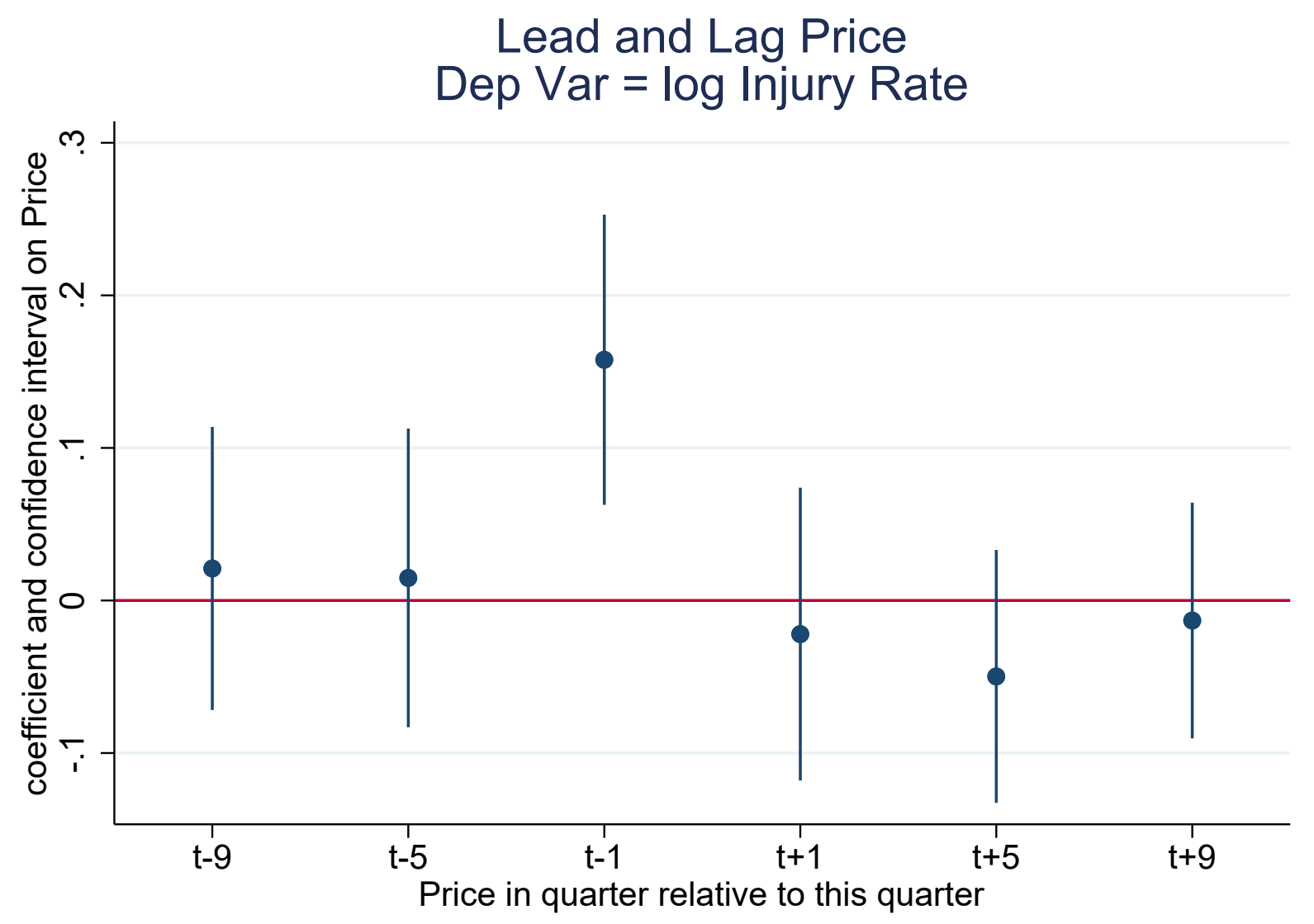

Notes: The figure plots point estimate and 95\% confidence intervals from an OLS regression akin to Equation 11 , but which also includes the specified leads and more distant lags of Price. The dependent variable is the log of the mine's quarterly injury rate. 
Table 1: Range of Price Data and Number of Mines for Each Commodity in our Sample

\begin{tabular}{lrrrl}
\hline & \multicolumn{2}{c}{ Price Series Range } & \multirow{2}{*}{ Number of mines } & Source \\
\cline { 2 - 3 } Commodity & First year & Last year & & \\
\hline Alumina & $1983 \mathrm{q} 1$ & $2015 \mathrm{q} 1$ & 14 & LME \\
Aluminum Ore-Bauxite & $1983 \mathrm{q} 1$ & $2015 \mathrm{q} 1$ & 17 & LME \\
Antimony Ore & $2010 \mathrm{q} 1$ & $2015 \mathrm{q} 1$ & 1 & Datastream \\
Cobalt Ore & $2011 \mathrm{q} 3$ & $2013 \mathrm{q} 1$ & 1 & Datastream \\
Copper Ore NEC & $1983 \mathrm{q} 1$ & $2015 \mathrm{q} 1$ & 132 & LME \\
Gold Ore & $1983 \mathrm{q} 3$ & $2015 \mathrm{q} 1$ & 1,753 & IMF \\
Iron Ore & $1983 \mathrm{q} 3$ & $2015 \mathrm{q} 1$ & 103 & IMF \\
Lead-Zinc Ore & $1993 \mathrm{q} 4$ & $2015 \mathrm{q} 1$ & 31 & LME \\
Molybdenum Ore & $1987 \mathrm{q} 1$ & $2015 \mathrm{q} 1$ & 12 & LME \\
Nickel Ore & $1984 \mathrm{q} 1$ & $2015 \mathrm{q} 1$ & 3 & LME \\
Platinum Group Ore & $1983 \mathrm{q} 1$ & $2015 \mathrm{q} 1$ & 7 & Datastream \\
Silver Ore & $1983 \mathrm{q} 1$ & $2015 \mathrm{q} 1$ & 250 & Datastream \\
Tin Ore & $1983 \mathrm{q} 1$ & $1998 \mathrm{q} 2$ & 2 & LME \\
Uranium Ore & $1983 \mathrm{q} 1$ & $2015 \mathrm{q} 1$ & 167 & IMF \\
Uranium-Vanadium Ore & $1983 \mathrm{q} 1$ & $2012 \mathrm{q} 2$ & 49 & Datastream \\
Zinc & $1983 \mathrm{q} 1$ & $2015 \mathrm{q} 1$ & 9 & LME \\
\hline
\end{tabular}

Notes: Price data are as described in text. Sources: LME = London Metals Exchange; $\mathrm{IMF}=\mathrm{IMF}$ Primary Commodity Price Database. 
Table 2: Summary Statistics on Main Dependent Variables

\begin{tabular}{lccc}
\hline Variable & $\mathrm{N}$ & Mean & Std. Dev. \\
\hline Average employment & 37,379 & 128.13 & 259.78 \\
Total working hours & 37,379 & $66,737.79$ & $135,898.46$ \\
Number of routine inspections this quarter & 37,379 & 0.50 & 0.53 \\
Total number of injuries this quarter & 37,379 & 1.85 & 3.83 \\
Injury rate (number of injuries per 100 full-time workers) & 37,379 & 1.92 & 8.82 \\
Total number of violations this quarter & 18,176 & 7.71 & 13.79 \\
\hline
\end{tabular}

Notes: All variables are top-coded at the 99th percentile. See text for details on how variables are constructed. 


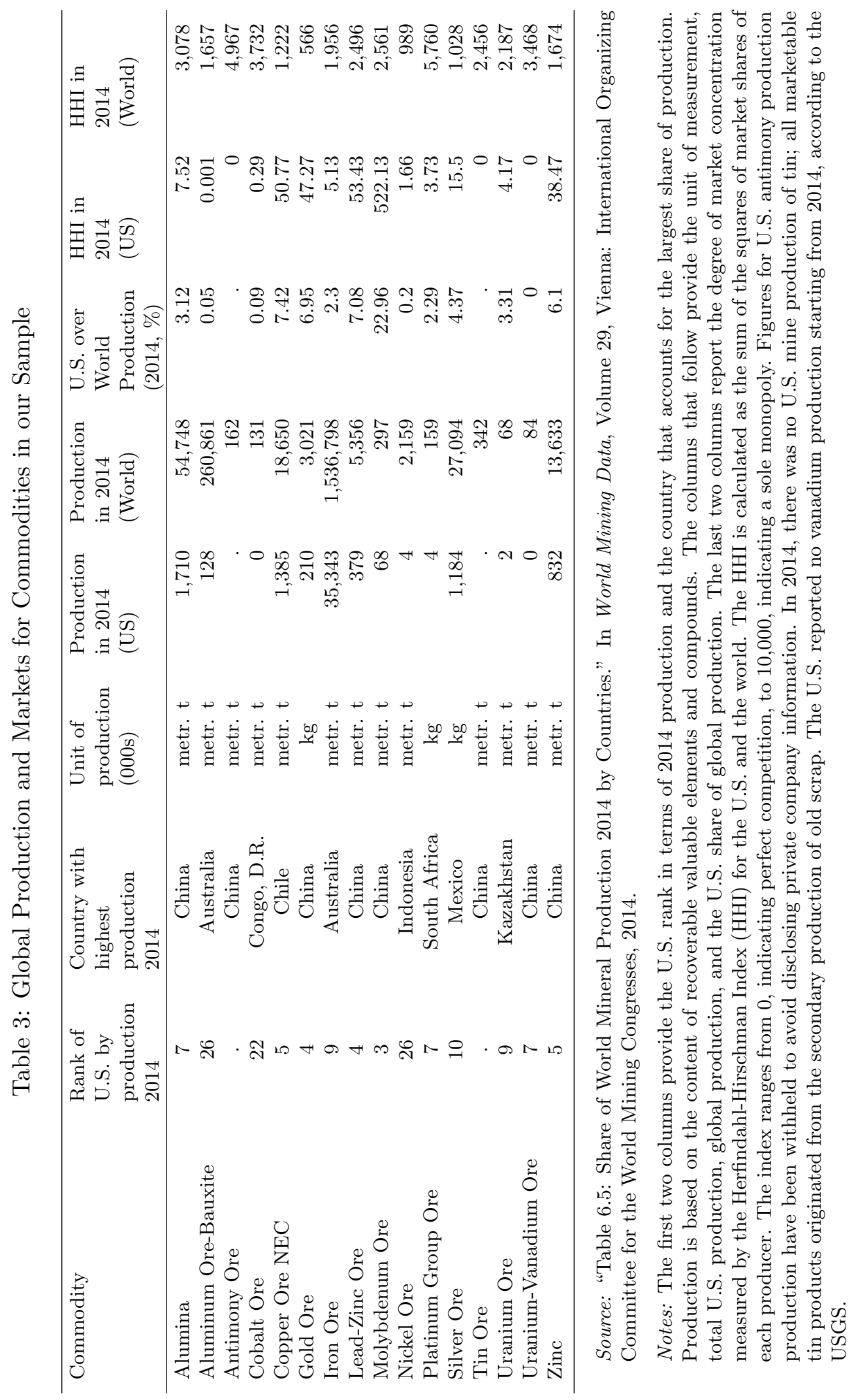


Table 4: Price Shocks and Mine Production at the Extensive and Intensive Margin

\begin{tabular}{|c|c|c|c|c|c|c|}
\hline & \multirow[t]{2}{*}{ (1) } & \multirow[t]{2}{*}{$(2)$} & \multirow{2}{*}{\multicolumn{2}{|c|}{$\begin{array}{c}(3) \\
\text { Dep } \operatorname{Var}=\Delta \log \text { of: }\end{array}$}} & \multirow[t]{2}{*}{$(5)$} & \multirow[t]{2}{*}{$(6)$} \\
\hline & & & & & & \\
\hline & \multicolumn{2}{|c|}{ \# Active Mines } & \multicolumn{2}{|c|}{ \# Employees } & \multicolumn{2}{|c|}{ Total Working Hours } \\
\hline$\Delta \log (\text { Price })_{j t-1}$ & $\begin{array}{c}0.090^{* * *} \\
(0.018)\end{array}$ & $\begin{array}{l}0.049^{*} \\
(0.026)\end{array}$ & $\begin{array}{c}0.238^{* * *} \\
(0.042)\end{array}$ & $\begin{array}{c}0.140^{* * *} \\
(0.044)\end{array}$ & $\begin{array}{c}0.328^{* * *} \\
(0.071)\end{array}$ & $\begin{array}{c}0.227^{* * *} \\
(0.086)\end{array}$ \\
\hline$\Delta \log (\text { Price })_{j t-2}$ & & $\begin{array}{c}0.020 \\
(0.037)\end{array}$ & & $\begin{array}{c}0.063 \\
(0.047)\end{array}$ & & $\begin{array}{l}-0.000 \\
(0.088)\end{array}$ \\
\hline$\Delta \log (\text { Price })_{j t-3}$ & & $\begin{array}{c}0.022 \\
(0.037)\end{array}$ & & $\begin{array}{c}0.080^{* *} \\
(0.039)\end{array}$ & & $\begin{array}{c}0.118 \\
(0.078)\end{array}$ \\
\hline$\Delta \log (\text { Price })_{j t-4}$ & & $\begin{array}{c}0.087^{* * * *} \\
(0.028)\end{array}$ & & $\begin{array}{l}0.097 * * \\
(0.040)\end{array}$ & & $\begin{array}{c}0.157 * * \\
(0.074)\end{array}$ \\
\hline $\begin{array}{l}\text { Sum of Lags } \\
\text { Std. Err. }\end{array}$ & & $\begin{array}{c}0.177^{* * * *} \\
(0.024)\end{array}$ & & $\begin{array}{c}0.380 * * * \\
(0.059)\end{array}$ & & $\begin{array}{c}0.502^{* * *} \\
(0.098)\end{array}$ \\
\hline Unit of observation & $\begin{array}{l}\text { Commodity- } \\
\text { Quarter }\end{array}$ & $\begin{array}{l}\text { Commodity- } \\
\text { Quarter }\end{array}$ & $\begin{array}{l}\text { Mine- } \\
\text { Quarter }\end{array}$ & $\begin{array}{l}\text { Mine- } \\
\text { Quarter }\end{array}$ & $\begin{array}{l}\text { Mine- } \\
\text { Quarter }\end{array}$ & $\begin{array}{l}\text { Mine- } \\
\text { Quarter }\end{array}$ \\
\hline Observations & 1,508 & 1,465 & 37,325 & 35,662 & 37,325 & 35,662 \\
\hline $\mathrm{R} 2$ & 0.340 & 0.337 & 0.020 & 0.023 & 0.012 & 0.013 \\
\hline Commodities & 16 & 16 & 16 & 16 & 16 & 16 \\
\hline
\end{tabular}

Notes: Each column displays results from an OLS regression.The dependent variable in Columns 1-2 is the 4-quarter $\log$ difference in the number of active mines producing a commodity at the end of a given quarter. In the remaining columns, it is the 4-quarter log difference in the number of employees (or hours worked) in a mine. In Columns 1-2, observations are weighted by the number of active mines producing a commodity 4 quarters ago. SEs, clustered by commodity-quarter in Columns 1-2, and clustered two ways by mine and commodity-quarter in Columns 3-6, in parentheses.

*** $p<0.01,{ }^{* *} p<0.05, * p<0.1$ 
Table 5: Price Shocks and Worker Safety

\begin{tabular}{lcccc}
\hline & $(1)$ & $(2)$ & $(3)$ & $(4)$ \\
& \multicolumn{4}{c}{ Dep Var $=\Delta \log$ of: } \\
\cline { 2 - 5 } & $\begin{array}{c}\text { Injury } \\
\text { Count }\end{array}$ & $\begin{array}{c}\text { Injury } \\
\text { Rate }\end{array}$ & $\begin{array}{c}\text { Traumatic } \\
\text { Injuries }\end{array}$ & $\begin{array}{c}\text { Serious } \\
\text { Injuries }\end{array}$ \\
\hline & & & & \\
$\Delta \log (\text { Price })_{j t-1}$ & $0.137^{* * *}$ & $0.153^{* * *}$ & $0.103^{* * *}$ & $0.046^{* *}$ \\
& $(0.027)$ & $(0.047)$ & $(0.021)$ & $(0.022)$ \\
Observations & 37,325 & 37,325 & 37,325 & 37,325 \\
R2 & 0.014 & 0.005 & 0.009 & 0.006 \\
Commodities & 16 & 16 & 16 & 16 \\
\hline
\end{tabular}

Notes: Each column displays results from an OLS regression. The dependent variable in Columns 1-2 is the 4-quarter log difference in the number of active mines producing a commodity at the end of a given quarter. In the remaining columns, it is the 4-quarter log difference in the number of employees (or hours worked) in a mine. In Columns 1-2, observations are weighted by the number of active mines producing a commodity 4 quarters ago. SEs, clustered by commodity-quarter in Columns 1-2, and clustered two ways by mine and commodity-quarter in Columns 3-6, in parentheses.

*** $p<0.01,{ }^{* *} p<0.05, * p<0.1$ 
Table 6: Do Changes in Worker Composition Explain the Effect on Injuries?

\begin{tabular}{|c|c|c|c|c|c|c|}
\hline & (1) & $(2)$ & $(3)$ & (4) & (5) & (6) \\
\hline & \multicolumn{6}{|c|}{ Dep Var $=\Delta \log$ Injuries: } \\
\hline & Total & $\begin{array}{l}\text { Worker } \\
<6 \text { months } \\
\text { tenure }\end{array}$ & $\begin{aligned} & \text { Worker } \\
& \geq 6 \text { months } \\
& \text { tenure }\end{aligned}$ & $\begin{array}{l}\text { Worker } \\
\text { tenure } \\
\text { missing }\end{array}$ & $\begin{array}{l}\text { Involves } \\
\text { Contractor }\end{array}$ & $\begin{array}{l}\text { Does not } \\
\text { Involve } \\
\text { Contractor }\end{array}$ \\
\hline$\Delta \log (\text { Price })_{j t-1}$ & $\begin{array}{c}0.137^{* * *} \\
(0.027)\end{array}$ & $\begin{array}{c}0.146^{* * *} \\
(0.025)\end{array}$ & $\begin{array}{l}0.046^{*} \\
(0.024)\end{array}$ & $\begin{array}{c}0.046^{* * *} \\
(0.014)\end{array}$ & $\begin{array}{c}0.089^{* * *} \\
(0.020)\end{array}$ & $\begin{array}{c}0.078^{* * *} \\
(0.026)\end{array}$ \\
\hline Observations & 37,325 & 37,325 & 37,325 & 37,325 & 37,325 & 37,325 \\
\hline $\mathrm{R} 2$ & 0.014 & 0.012 & 0.009 & 0.004 & 0.008 & 0.009 \\
\hline Commodities & 16 & 16 & 16 & 16 & 16 & 16 \\
\hline
\end{tabular}

Notes: Each column displays results from an OLS regression in which the unit of observation is a mine-quarter. SEs, clustered two ways by mine and commodity-quarter, in parentheses.

*** $p<0.01, * * p<0.05,{ }^{*} p<0.1$ 
Table 7: Robustness Tests on Effects of Price Shocks on Worker Safety

\begin{tabular}{|c|c|c|c|c|c|}
\hline & (1) & $(2)$ & $\begin{array}{c}(3) \\
\text { Dep } \operatorname{Var}=\end{array}$ & (4) & $(5)$ \\
\hline & $\Delta \mathrm{lc}$ & Injuries: & $\Delta$ IHS Injuries: & $\log$ Injuries & Injuries \\
\hline & Baseline & $\begin{array}{l}\text { Cluster SE by } \\
\text { commodity }\end{array}$ & $\begin{array}{c}\text { Inverse } \\
\text { Hyperbolic Sign }\end{array}$ & $\begin{array}{l}\text { Fixed-effects } \\
\text { OLS }\end{array}$ & $\begin{array}{c}\text { Fixed-effects } \\
\text { Poisson }\end{array}$ \\
\hline$\Delta \log (\text { Price })_{j t-1}$ & $\begin{array}{c}0.137^{* * *} \\
(0.027)\end{array}$ & $\begin{array}{c}0.137^{* * *} \\
(0.027)\end{array}$ & $\begin{array}{c}0.173^{* * *} \\
(0.034)\end{array}$ & & \\
\hline $\log (\text { Price })_{j t-1}$ & & & & $\begin{array}{c}0.126^{* * *} \\
(0.035)\end{array}$ & $\begin{array}{l}0.122^{*} \\
(0.069)\end{array}$ \\
\hline Observations & 37,325 & 37,325 & 37,325 & 47,988 & 35,670 \\
\hline $\mathrm{R} 2$ & 0.014 & 0.014 & 0.013 & 0.645 & \\
\hline FD or FE? & FD & FD & FD & $\mathrm{FE}$ & $\mathrm{FE}$ \\
\hline Specification & OLS & OLS & OLS & OLS & Poisson \\
\hline Commodities & 16 & 16 & 16 & 16 & 14 \\
\hline
\end{tabular}

Notes: In Columns 1-2, the dependent variable is $\Delta \log$ (\# Injuries): the 4-quarter difference in the log of the number of injuries experienced by a mine. In Columns 3-4, the dependent variable is $\log$ (\# Injuries). The unit of observation is a mine-quarter. In Column 2, SEs are clustered by commodity and calculated using a wild bootstrap; in all other columns SEs are clustered two ways by mine and commodity-quarter.

*** $p<0.01,{ }^{* *} p<0.05,{ }^{*} p<0.1$ 
Table 8: Price Shocks and Compliance with Safety Regulations

\begin{tabular}{lcc}
\hline & \multicolumn{2}{c}{$(1)$} \\
& \multicolumn{2}{c}{ Dep Var $=\Delta$ log of: } \\
\cline { 2 - 3 } & $\begin{array}{c}\text { \# Violations, } \\
\text { Total }\end{array}$ & $\begin{array}{c}\text { \# High Negligence } \\
\text { Violations }\end{array}$ \\
\hline & & \\
$\Delta \log (\text { Price })_{j t-1}$ & $0.131^{* * *}$ & $0.051^{* *}$ \\
& $(0.044)$ & $(0.020)$ \\
Observations & 29,359 & 29,359 \\
R2 & 0.011 & 0.014 \\
Commodities & 16 & 16 \\
\hline
\end{tabular}

Notes: Each column displays results from an OLS regression. The unit of observation is a minequarter. $\Delta$ represents a 4-quarter difference (i.e., $\left.\Delta \log (\text { Price })_{j t-1}=\log (\text { Price })_{j t-1}-\log (\text { Price })_{j t-5}\right)$. SEs, clustered two ways by mine and commodityquarter, in parentheses.

*** $p<0.01,{ }^{* *} p<0.05, * p<0.1$ 
Table 9: Heterogeneous Effects of Price Shocks by Mine Type

\begin{tabular}{lcccc}
\hline & $(1)$ & $(2)$ & $(3)$ & $(4)$ \\
& \multicolumn{4}{c}{ Dep Var $=$} \\
\cline { 2 - 5 } & $\begin{array}{c}\Delta \log \\
\text { Employment }\end{array}$ & $\begin{array}{c}\Delta \log \\
\text { Hours }\end{array}$ & $\begin{array}{c}\Delta \log \\
\text { Injuries }\end{array}$ & $\begin{array}{c}\Delta \log \\
\text { Violations }\end{array}$ \\
\hline & $0.172^{* * *}$ & $0.249^{* * *}$ & $0.106^{* * *}$ & $0.107^{*}$ \\
$\Delta \log (\text { Price })_{j t-1}$ & $(0.046)$ & $(0.080)$ & $(0.029)$ & $(0.056)$ \\
& & & & \\
$\Delta \log (\text { Price })_{j t-1} \times$ Underground & $0.177^{* *}$ & $0.211^{*}$ & $0.084^{*}$ & 0.058 \\
& $(0.073)$ & $(0.128)$ & $(0.044)$ & $(0.074)$ \\
Observations & & & & \\
R2 & 37,325 & 37,325 & 37,325 & 29,359 \\
Commodities & 0.022 & 0.010 & 0.014 & 0.011 \\
\hline
\end{tabular}

Notes: Each column displays results from an OLS regression in which the unit of observation is a mine-quarter. SEs, clustered two ways by mine and commodityquarter, in parentheses.

*** $p<0.01,{ }^{* *} p<0.05,{ }^{*} p<0.1$ 


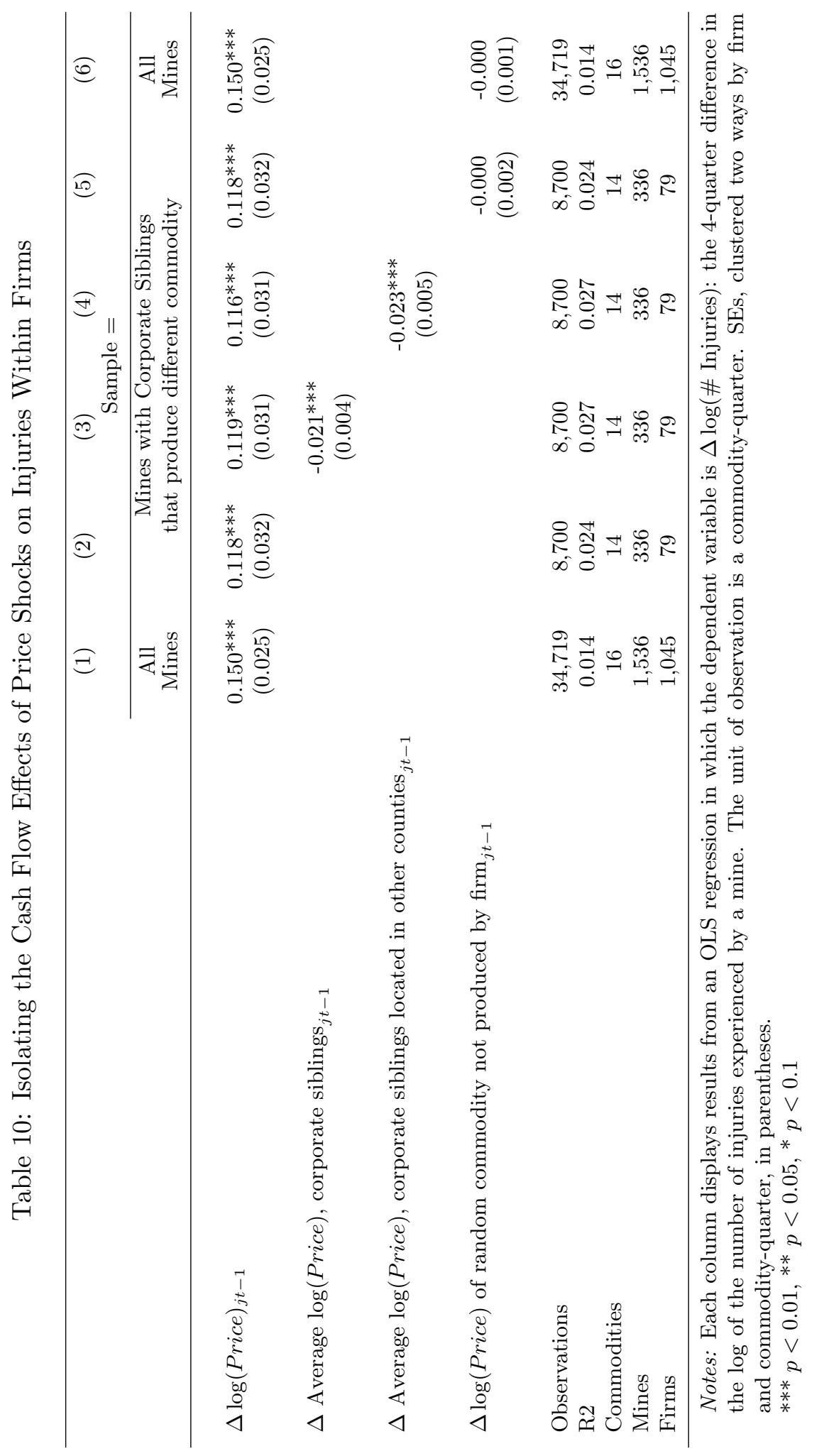




\section{A Theoretical Appendix}

In the model presented in Section 2, we assumed that the three inputs into firms' accidents (production, training, and safety equipment) were separable. In this appendix, we derive the key comparative statics of our model relaxing this assumption.

The inputs into the firm's "accident production function" might interact with each other. For example, the amount by which increased production raises accidents may be smaller the higher the level of training, and the higher the level of safety equipment. Additionally, following the intuition that each input on its own has diminishing returns, the marginal effect of training on accidents might be smaller when the level of safety equipment is higher (and vice versa). These examples would imply the following strict inequalities on the various cross derivatives of the production function:

$$
A_{q T}=A_{T q}=\frac{\partial^{2} A}{\partial q \partial T}<0 ; \quad A_{q E}=A_{E q}=\frac{\partial^{2} A}{\partial q \partial E}<0 ; \quad A_{T E}=A_{E T}=\frac{\partial^{2} A}{\partial T \partial E}>0 .
$$

Our goal is to determine how relaxing this assumption affects $\frac{d A}{d p}$ and $\frac{d A}{d x}$. Each of the First Order Conditions in Equation (2) are identical as in the case in which we assume separability in the main text. We note the Second Order Conditions (SOCs) here:

$$
\begin{aligned}
\pi_{q q} & =-\kappa\left[A_{q q}+A_{q T} T^{\prime}+A_{T} T^{\prime \prime}+\left(A_{T q}+A_{T T} T^{\prime}\right) T^{\prime}\right] \\
\pi_{q E} & =-\kappa\left[A_{q E}+A_{T E} T^{\prime}\right] \\
\pi_{E q} & =-\kappa\left[A_{E q}+A_{E T} T^{\prime}\right] \\
\pi_{E E} & =-\kappa A_{E E}
\end{aligned}
$$

Thus, the Hessian matrix $H$ is:

$$
H=\left[\begin{array}{cc}
\pi_{q q} & \pi_{q E} \\
\pi_{E q} & \pi_{E E}
\end{array}\right]
$$


$\pi(q, E)$ has a maximum at $\left(q^{*}, E^{*}\right)$ if

$$
\begin{aligned}
& \pi_{q q}<0 \\
& \pi_{E E}<0 \\
& \pi_{q q} \pi_{E E}-\pi_{q E} \pi_{E q}>0
\end{aligned}
$$

Next, we compute the comparative statics in the general case. Turning first to the components of $\frac{d A}{d p}$, we have that:

$$
\frac{\partial q}{\partial p}=-\frac{\kappa\left(-A_{E E}-R_{p}\left[A_{q E}+A_{T E} T^{\prime}\right]\right)}{\operatorname{det}(H)}
$$

where $\operatorname{det}(H)$ is the determinant of the Hessian matrix of second derivatives. Given our assumptions about the cross-partial derivatives above, the numerator is negative, just as it is if inputs are separable. The denominator (The Hessian) must be positive by the second order conditions, making the entire term positive. Thus, $\frac{\partial q}{\partial p}>0$.

Employing similar reasoning,

$$
\frac{\partial E}{\partial p}=\underbrace{-\frac{\kappa}{\operatorname{det}(H)}}_{<0}([\underbrace{A_{E q}}_{<0}+\underbrace{A_{E T} T^{\prime}}_{<0}]+\underbrace{R_{p}}_{<0}[\underbrace{A_{q q}}_{>0}+\underbrace{A_{q T} T^{\prime}}_{>0}+\underbrace{A_{T} T^{\prime \prime}}_{>0}+(\underbrace{A_{T q}}_{<0}+\underbrace{A_{T T} T^{\prime}}_{<0}) \underbrace{T^{\prime}}_{<0}])>0
$$

Thus, $\frac{\partial E}{\partial p}>0$, just as under the assumption of separable inputs.

\section{Comparative Statics of Other Changes in the Firm's Financial Position}

Moving to $\frac{d A}{d x}$, how $x$ (a shock that only affects the firm's financial position) affects the firm's choice of $q$ and $E$ is given by:

$$
\begin{aligned}
& \frac{\partial q}{\partial x}=-\frac{-R_{x}(i) \times \kappa\left(A_{q E}+A_{T E} T^{\prime}\right)}{\operatorname{det}(H)}>0 \\
& \frac{\partial E}{\partial x}=\underbrace{\frac{\kappa}{\operatorname{det}(H)}}_{<0}(\underbrace{R_{x}}_{<0}[\underbrace{A_{q q}}_{>0}+\underbrace{A_{q T} T^{\prime}}_{>0}+\underbrace{A_{T} T^{\prime \prime}}_{>0}+(\underbrace{A_{T q}}_{<0}+\underbrace{A_{T T} T^{\prime}}_{<0})_{<0}^{T^{\prime}}])>0
\end{aligned}
$$

where, as before, $\operatorname{det}(H)$ is the determinant of the Hessian matrix, $H$, that is the matrix of second 
derivatives with respect to $q$ and $E$. As it was under the separability assumption in the main text, $\frac{\partial E}{\partial x}$ is strictly positive ${ }^{30}$

Equation A.11 shows that while a pure liquidity shock does not affect the firm's output demand conditions, the shock might affect the amount of output $q$ produced depending on how inputs interact to produce accidents. If inputs are non-separable, then a positive change in $x$ can increase production, thus raising accidents. ${ }^{31}$ This contrasts with the case in which inputs are separable, in which case output is completely unresponsive to the liquidity shock that reduces the costs of $E$.

In conclusion, if we relax the assumption that inputs into producing accidents are separable, the only substantive difference is that $\frac{d A}{d x}$ is ambiguous, rather than unambiguously negative. This difference arises since $\frac{d q}{d x}$ is positive, rather than zero. However, given the evidence from multiple studies that improvements in firms' financial position leads to fewer injuries (i.e. that $\frac{d A}{d x}$ is negative), it seems plausible that the assumption of separable inputs holds approximately in the real-world. All other comparative statics are qualitatively the same.

\footnotetext{
${ }^{30}$ Comparing equations (A.12) and (A.10) shows that a shock that eases liquidity causes the firm to increase $E$ by less than an increase in $p$ induces it to do. This difference arises only if inputs are non-separable; because an increase in $p$ raises the value of production, this gives the firm an additional reason to increase $E$ by dampening the extent to which increasing $q$ would otherwise leads to more accidents $\left(A_{q E}\right)$. If, on the other hand, $A_{q E}=0$, as we assumed in the main text, then a change in $x$ has an identical effect on $E$ as does a change in $p$.

${ }^{31}$ The mechanism behind this result is as follows. A positive change in $x$ makes safety equipment $E$ cheaper for the firm, inducing it to use more of it. If more equipment dampens the extent to which increasing $q$ increases accidents $A$ (i.e. if $A_{q E}<0$ ), more $E$ makes it less costly to expand production. Furthermore, if more equipment makes a marginal increase in training less effective at reducing accidents, $\left(A_{T E}>0\right)$, then having more $E$ makes it profitable for the firm to shift resources away from training. Both of these forces lead the firm to increase production in response to a positive liquidity shock.
} 


\section{B Appendix Tables and Figures}

Figure B.1: The Time-Series Relationship Between Commodity Prices and U.S. Production of Silver and Gold

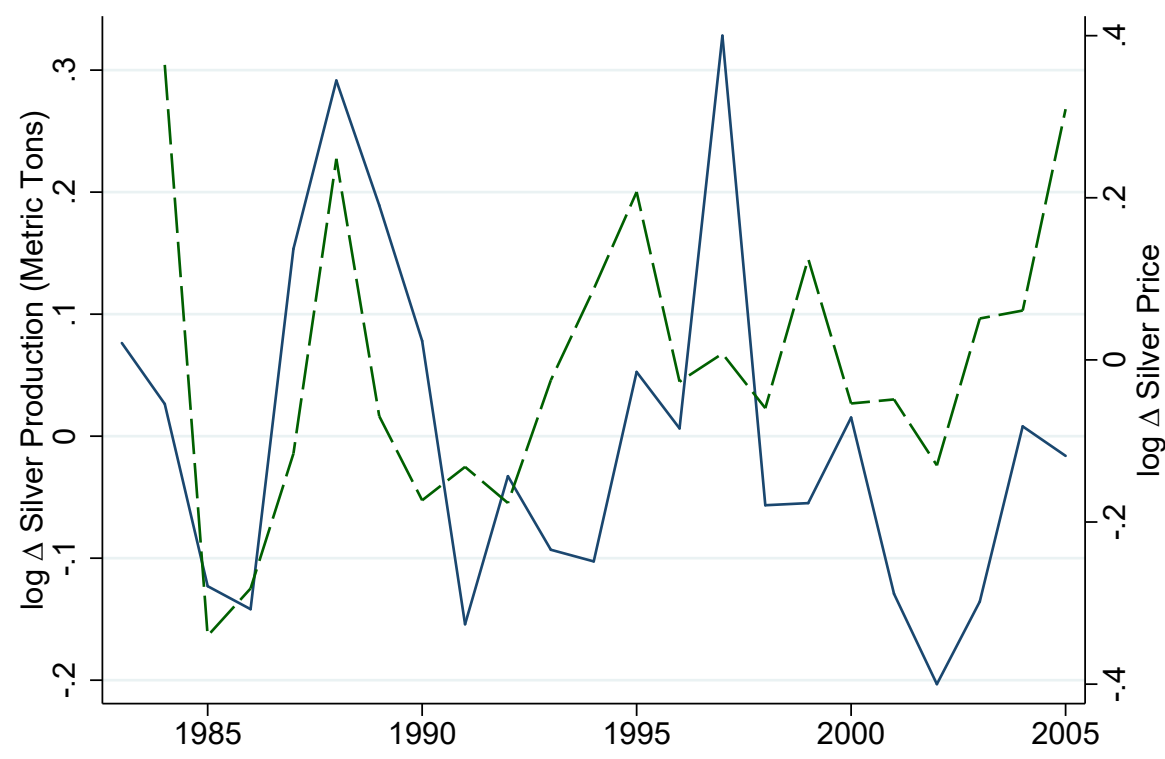

- $\log \Delta$ Silver Production $\quad-\quad \log \Delta$ Silver Price, lag 1 year

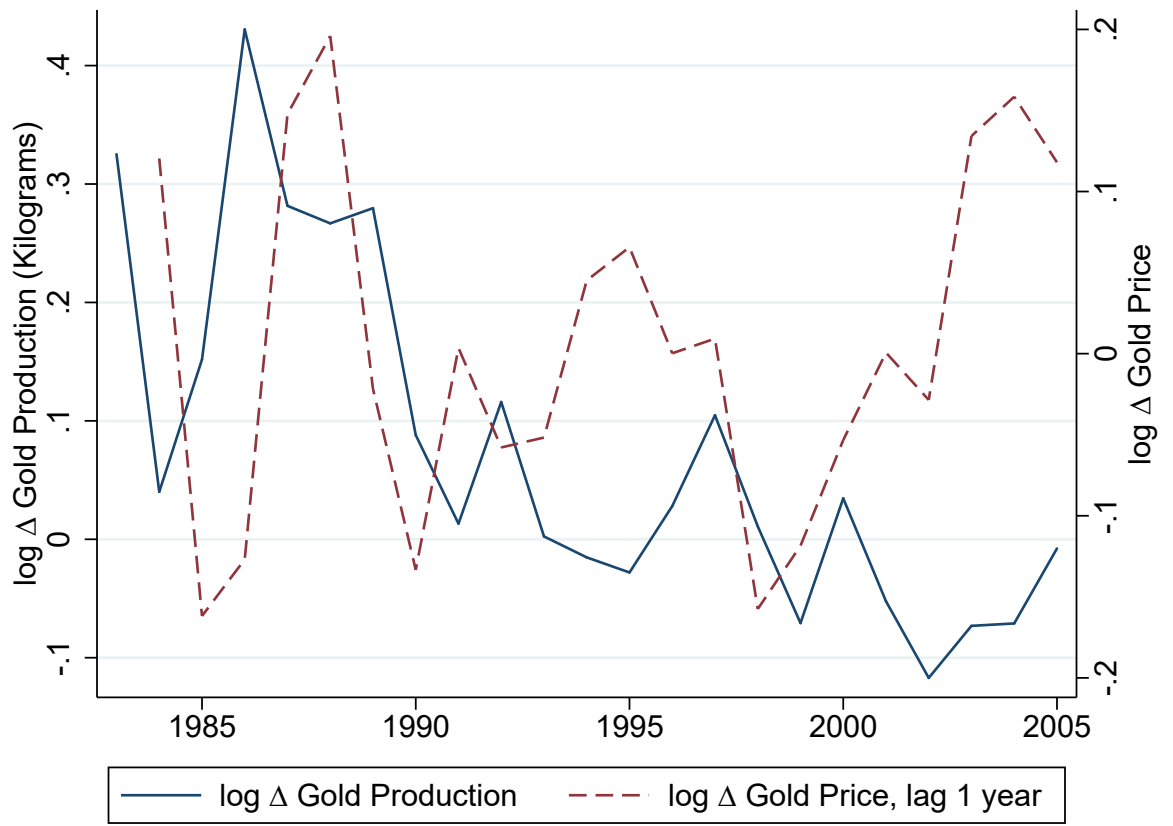

Notes: The data on annual production comes from the USGS Annual Minerals Survey. 
Figure B.2: Commodity Prices and Mining Companies' Exploration Budgets

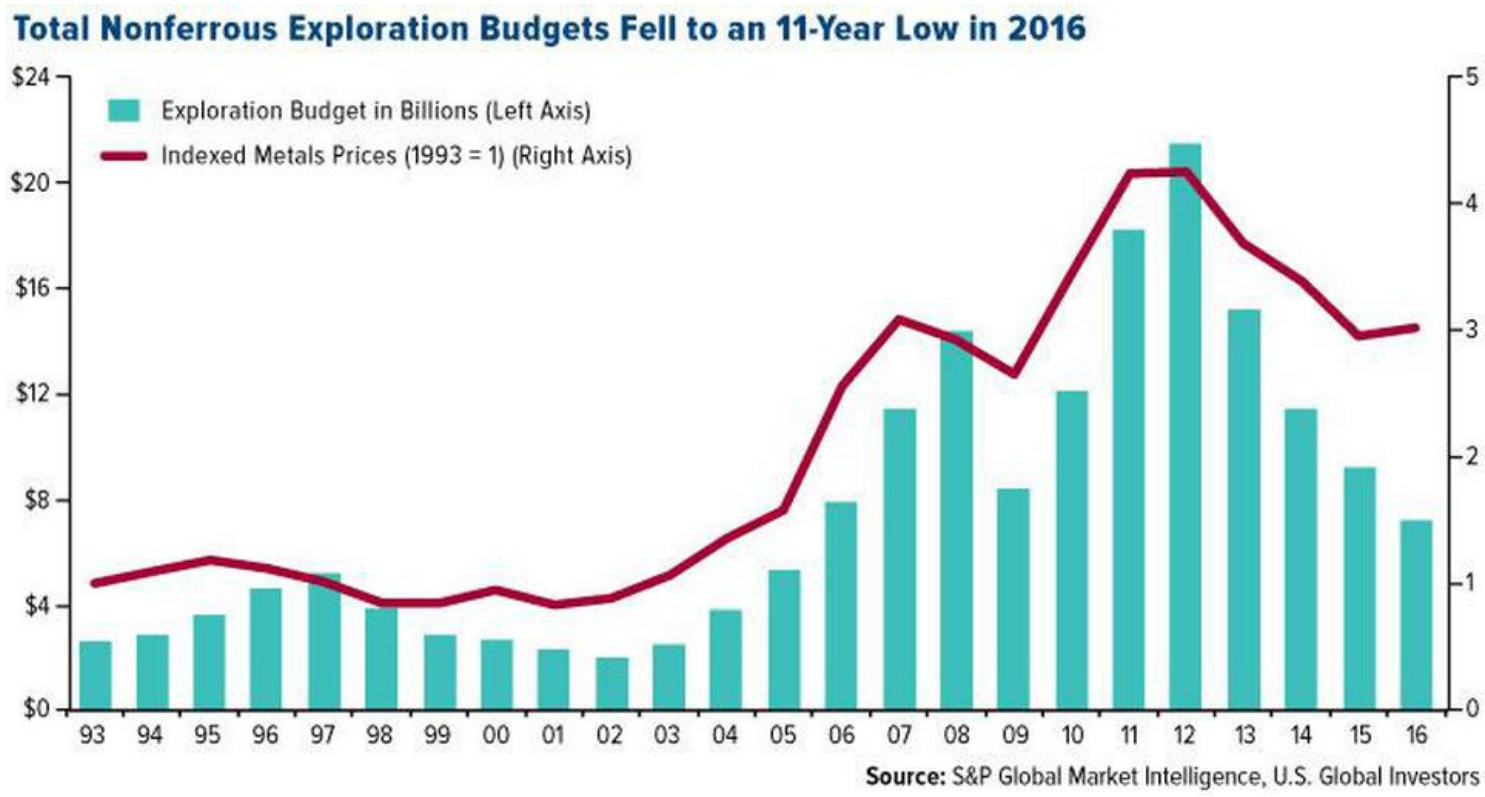

Source: S\&P Global Market Intelligence. Data as of Oct. 29, 2018. S\&P Global Market Intelligence obtains the data used in its Corporate Exploration Strategies (CES) series, which is an annual survey of commercially oriented nonferrous mining or exploration companies. All historical exploration budget amounts throughout this report represent dollars of the day and have not been adjusted for inflation. 
Table B.1: Summary Statistics on All Other Dependent Variables

\begin{tabular}{lccc}
\hline Variable & $\mathrm{N}$ & Mean & Std. Dev. \\
\hline \# injuries involving workers with $\geq 6$ months experience at the mine & 37,379 & 1.42 & 3.22 \\
\# injuries involving workers with $<$ 6 months experience at the mine & 37,379 & 0.28 & 0.85 \\
\# injuries with experience at this mine of worker missing & 37,379 & 0.17 & 0.68 \\
Number of incidents involving a contractor & 37,379 & 0.26 & 0.97 \\
Number of incidents that do not involve a contractor & 37,379 & 1.61 & 3.53 \\
Number of injuries caused by over-exertion & 37,379 & 0.46 & 1.26 \\
Number of injuries caused by striking object & 37,379 & 0.72 & 1.66 \\
Number of injuries caused by worker falling & 37,379 & 0.27 & 0.75 \\
\hline
\end{tabular}

Notes: All variables are top-coded at the 99th percentile. See text for details on how variables are constructed. 
Table B.2: Price Shocks and Various Types of Injuries

\begin{tabular}{|c|c|c|c|c|}
\hline & (1) & $(2)$ & $(3)$ & $(4)$ \\
\hline & \multicolumn{4}{|c|}{ Dep $\operatorname{Var}=\Delta \log$ Injuries Involving: } \\
\hline & $\begin{array}{c}\text { Over } \\
\text { Exertion }\end{array}$ & $\begin{array}{l}\text { Struck by } \\
\text { Object }\end{array}$ & $\begin{array}{c}\text { Contact with } \\
\text { Machinery }\end{array}$ & $\begin{array}{c}\text { Worker } \\
\text { Fall }\end{array}$ \\
\hline$\Delta \log (\text { Price })_{j t-1}$ & $\begin{array}{c}0.037^{*} \\
(0.020)\end{array}$ & $\begin{array}{c}0.087^{* * *} \\
(0.022)\end{array}$ & $\begin{array}{c}0.051^{* * *} \\
(0.017)\end{array}$ & $\begin{array}{c}0.038^{* *} \\
(0.015)\end{array}$ \\
\hline Observations & 37,325 & 37,325 & 37,325 & 37,325 \\
\hline $\mathrm{R} 2$ & 0.006 & 0.007 & 0.004 & 0.004 \\
\hline Specification & OLS & OLS & OLS & OLS \\
\hline Commodities & 16 & 16 & 16 & 16 \\
\hline
\end{tabular}

Notes: Each column displays results from an OLS regression in which the unit of observation is a mine-quarter. SEs, clustered two ways by mine and commodity-quarter, in parentheses. 